\title{
Knowledge Transmission Through the Lens of Lithic Production: a Case Study from the Pastoral Neolithic of Southern Kenya
}

\author{
Steven T. Goldstein ${ }^{1}$ (D)
}

Published online: 30 June 2018

(C) The Author(s) 2018

\begin{abstract}
This paper examines theoretical and methodological approaches to measuring and discussing skill in the archaeological record. Focusing specifically on evaluating skill in lithic production, a case study is presented which quantifies production errors in several assemblages of obsidian blades from early pastoralist sites of the Elmenteitan culture in southern Kenya (c. 3000-1400 BP). Analysis of error frequency through the blade core reduction sequence and relationships between error types suggest that production errors in blade production may relate, in part, to the presence of novices' practice and learning. Comparison among assemblages shows that sites closer to the primary obsidian quarry site display higher proportions of blade production errors. Communities-of-practice theory is drawn upon to interpret these patterns and to generate hypotheses for how early Elmenteitan producing herders may have structured knowledge transmission related to lithic production. Finally, the paper discusses how lithic learning may have been integrated into broader social systems relating to pastoralist resilience in eastern Africa.
\end{abstract}

Keywords Lithics $\cdot$ Learning $\cdot$ Communities-of-practice $\cdot$ Pastoralism $\cdot$ Africa $\cdot$ Kenya Elmenteitan

\section{Introduction}

Archaeology is built on patterns. The cultural units we construct are based around cooccurring traits like artifact styles, and we understand past peoples' relationships with

Electronic supplementary material The online version of this article (https://doi.org/10.1007/s10816-0189387-x) contains supplementary material, which is available to authorized users.

Steven T. Goldstein

goldstein@sh.mpg.de

1 Max Planck Institute for the Science of Human History, Kahlaische Strasse 10, 07745 Jena, Germany 
environments by identifying patterns in subsistence and technological remains (Costin 2001). It is only through the recognition of patterns that we notice exceptions and deviations, presenting opportunities to discuss agency, resistance, and gendered activities in the past (Bleed 2008; Creese 2012; Finlay 1997; Stahl 2008; Stark et al. 2008; Stout 2005; Wendrich 1999, 2013). Whether a pattern lasts for millions of years or only a few generations, its existence derives from systems of knowledge transmission. This is by no means unique to the Homo clade, but so far, only humans have demonstrated such variability in how knowledge transfer is integrated into social and cultural systems. Whether one prefers to think of these behaviors as mediated by cultural habitus (Bourdieu 1977) or simply another adaptive strategy, knowledge transmission has undeniably been a critical part of human behavior that has shaped both the archaeological record and our interpretation of it.

Archaeologies of "learning" are on the rise, with emphasis on identifying knowledge transmission in the domain of stone tool production (see Bamforth and Finlay 2008; Ferguson 2008; Högberg et al. 2015; Hiscock 2014; Lillehammer 2015; Takakura 2013; Tostevin 2013; Wendrich 2013). In part, this is because lithics are the most abundant form of material culture in the archaeological record and are often one of the only available datasets for pursuing social questions in the deeper past. Other archaeologists seek to identify learning because the copious material remnants of stone-tool-making "practice" may be affecting technological interpretations grounded in evolutionary theory or Human Behavioral Ecology (e.g., Goodale and Andrefsky 2015; Surovell 2012). Identifying learning is difficult; however, archaeologists have developed a suite of innovative methodologies and analytical techniques for approaching the issue. These methods build off the observation that individuals learning to make stone tools - like many other complex tasks-will make mistakes at a higher rate and with greater severity than will experienced knappers (Ferguson 2008; Finlay 2008; Milne 2005, 2012). Production errors then become useful correlates for identifying different levels of skill in lithic assemblages, albeit with significant limitations. Further developing this critical avenue of archaeological discourse requires more expanded efforts to identify and discuss learning in a greater diversity of time periods, regional contexts, subsistence economies, and forms of technological organization.

Here, I present a case study assessing the error rates in obsidian blade assemblages from seven sites of the Elmenteitan tradition of the Pastoral Neolithic (PN) (c. 3000$1400 \mathrm{BP}$ ) in order to explore the issue of learning and knowledge transmission among the earliest cattle-herding communities in East Africa. In southern Kenya, the PN involved a mosaic of coexisting hunter-gatherer and food-producer groups with discrete ceramic styles, mortuary traditions, and lithic production strategies (Ambrose 1980, 1984a, b, 2001; Bower 1991; Marshall et al. 2011). Each group would have required internal social structures to maintain the markers of its own cultural (and likely ethnolinguistic; see Ambrose 1980, 2001) identity, and it is even possible that these diverse PN entities employed very different social strategies for sustaining knowledge transmission (see Ambrose 2001; Gifford Gonzalez 1998; Marshall et al. 2011). One of these cultural-historical groups known as the "Elmenteitan" presents a particularly strong opportunity to investigate learning due to Elmenteitan assemblages exhibiting a uniform production strategy at sites distributed across diverse ecological zones. Elmenteitan communities also relied on obsidian from a single obsidian source group 
for almost all of their stone tool production, allowing for relative control over raw material variation and distance-from-source effects.

The goal here is not just to contribute analytical techniques for measuring error rates as a correlate for learning, but also to integrate quantitative data with discussions of the underlying social behaviors of knowledge transmission. Fortunately, the rich ethnographic record of East Africa includes similar subsistence economies in similar ecological contexts, providing a firm basis for building structural analogies for how ancient social institutions involved in learning may have been organized (sensu Wylie 1989). Even though such discussions will be inherently speculative (see Wendrich 2013), they are important for advancing discourse on knowledge transmission in the archaeological past, ultimately enriching archaeological narratives.

\section{Background}

\section{African Pastoralism}

Lifeways that were economically and ideologically centered on the ownership and movement of cattle originated in the eastern Sahara by c. 8000 BP, before the adoption of domesticated crops (Marshall and Hildebrand 2002). Increasing aridity in the Middle Holocene led to the recession of lakes, riverine systems, and grasslands that had dominated the Sahara, limiting the availability of wild resources (Kuper and Kröpelin 2006). Livestock became increasingly important as people moved toward river systems like the Nile and Niger rivers and then later southward into Sub-Saharan Africa. African pastoralism is thus associated with more mobile lifeways, influencing the persistence of social systems with less pronounced social inequality than are observed for other trajectories of food production. Alternative forms of social organization developed, including the formation of age-grade institutions and heterarchical "gerontocracies" (see Foner and Kertzer 1978; Peristiany 1951; Spencer 1965). These kinds of institutions are universal to ethnohistoric herding societies in East Africa, wherein they provide a critical role in both inter- and intra-generational knowledge transmissions. Age-grade structures create and reinforce social bonds but are also a practical way of organizing labor given the constraints of mobile herding in drought-prone environments. When African pastoralists began experimenting with these social strategies is unknown.

Highly mobile herders remained largely ephemeral on the landscape until the first domesticated cattle, goat, and sheep appear in the Lake Turkana Basin of northern Kenya by around 4500 cal. BP (Hildebrand and Grillo 2012; Marshall et al. 1984). A slow trickle of livestock into the Central Rift Valley of southern Kenya preceded the appearance of widespread herding traditions across East Africa after 3200 BP. Large domestic sites like Narosura (Odner 1972), Ngamuriak (Robertshaw 1990), and Hyrax Hill (Leakey et al. 1943) begin to appear at this time, and there is evidence for the formation of larger networks of interaction and exchange (Ambrose 2001, 2002; Robertshaw 1988). Diverse socio-economic dynamics underlie the spread of herding, with at least two discrete cultural traditions associated with livestock co-existing both alongside one another, and with hunter-gatherer communities in the Central Rift and along Lake Victoria (Ambrose 2001; Marshall et al. 2011). The first entity with clear evidence for economies based on domesticated animals is the Savanna Pastoral Neolithic (SPN). The 
SPN seems to encompass a range of groups with diverse ceramic decorations, including Nderit, Ileret, Akira, Maringishu, and particularly Narosura ware. SPN sites exhibit different degrees of wild fauna exploitation, variable lithic tool forms and production styles, and use of multiple local and distant raw material sources for stone tool production. There is a general preference for obsidian sources in the southern and western Lake Naivasha basin, and this along with a preference for cairn burial constitutes the few consistent attributes linking SPN producing communities (Ambrose 2001, 2012; Merrick et al. 1990). It is likely that the SPN is really an archaeological catch-all category for a diverse range of loosely affiliated groups with different social and economic practices, possibly including hunter-gatherers who adopted herding.

\section{The Elmenteitan Culture of the Pastoral Neolithic}

By c. 3000 BP, a second pastoralist tradition appears in southern Kenya. Labeled the "Elmenteitan" after type sites around Lake Elmenteita, this group of assemblages appears as a more consistent and uniform cultural entity that persists until the arrival of iron technology around 1400 BP. Sites of the Elmenteitan traditions are widely dispersed in highland ecotones from the Central Rift to the Lake Victoria Basin of western Kenya, encompassing the whole of the Loita-Mara Plains (Fig. 1). Elmenteitan pottery is minimally decorated and mica-tempered with lugs and spouts. Despite a long period of coexistence with SPN groups, there is no current evidence for ceramic exchange (Ambrose 1982; Robertshaw and Collett 1983). Elmenteitan sites in some regions demonstrate highly specialized herding economies wherein over $99 \%$ of the identifiable fauna are domesticated (Marshall 1990; Simons 2004). Elmenteitan material culture is also associated with rockshelter and crevice burials, rather than the burial cairns associated with the SPN.

The primary obsidian source exploited by Elmenteitan groups was the Elmenteitan Obsidian Quarry, located on the upper slopes of the Mt. Eburru volcanic complex (Ambrose 2001, 2012). While SPN and hunter-gatherer groups used obsidian from various sources, Elmenteitan groups largely ignored those sources in favor of a geochemically and visually distinct green-hued obsidian from Mt. Eburru, which makes up 7090\% of lithic assemblages at Elmenteitan sites up to $250 \mathrm{~km}$ away (Ambrose 2012; Merrick et al. 1990; Merrick and Brown 1984). Sourcing projects continue to confirm that Mt. Eburru is the origin of this green obsidian. Both Ambrose (2001) and Robertshaw $(1988,1990)$ have argued that Elmenteitan groups participated in a regional obsidian exchange or distribution network and were otherwise more socially cohesive (see also Gifford-Gonzalez 1998). Maintenance of material patterns, long distance exchange relationships, and new evidence for communal participation in obsidian quarrying at the major Elmenteitan obsidian source all support this proposal (Goldstein and Munyiri 2017).

Elmenteitan lithic assemblages consistently display derived traits indicative of maintained technological traditions that differentiate them from SPN or hunter-gatherer tool kits (see Ambrose 2001, 2002; Goldstein 2018; Leakey and Leakey 1950; Nelson 1980). Elmenteitan producers used obsidian from Mt. Eburru sources to produce large flat blades with heavily prepared striking platforms (Fig. 2). Blades were intensively utilized as backed knives, endscrapers, or were segmented into blanks for burins, or small cores (Ambrose 1984a, 2001; Nelson 1980). Elmenteitan geometric backed pieces exhibit a uniformly small size compared to those from SPN sites (Ambrose 2002; Goldstein and Shaffer 2017). The uniformity of the Elmenteitan cultural package led Ambrose (1982) to 


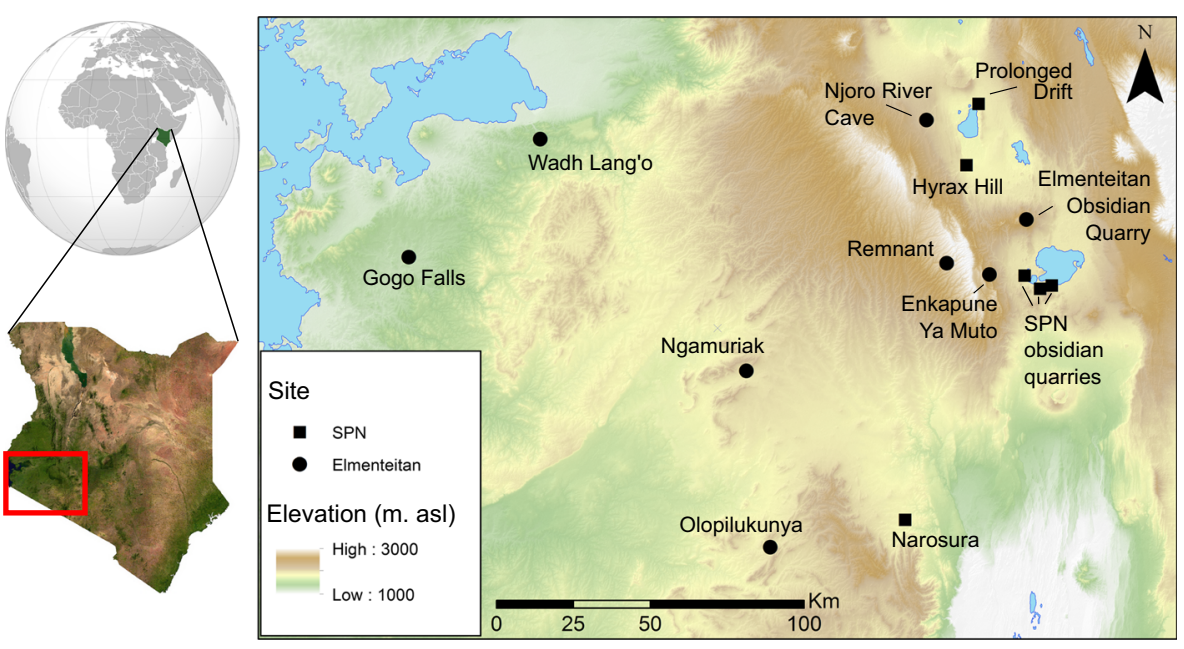

Fig. 1 Map of the research area in southwestern Kenya with sampled Elmenteitan sites and SPN sites mentioned in the text. Elevation data from NASA SRTM 3-arc second imagery

propose the Elmenteitan represented an initial spread of Nilotic speaking populations into the region. The suite of material culture traditions, settlement strategies, and mortuary practices that are discretely maintained at Elmenteitan sites and the exclusion of SPN or hunter-gatherer archeological patterns reflect, at the very least, aspects of a social and economic identity that people chose to pass on and maintain for nearly 2000 years.

\section{Structures of Learning in the Archaeological Record}

Lithics, one of the most abundant forms of material culture in the Pastoral Neolithic record, provide an avenue for reconstructing social systems, if we recognize technology has a role in social (re-)production and change (Agbe-Davies 2009; Bamforth and Finlay 2008; Dobres and Hoffman 1994; Ferguson 2008; Lemonnier 1993; van der Leeuw 1993). This is to say that the spatial and behavioral patterns surrounding tool manufacture, use, repair, and discard are socially structured. Ethnoarchaeological studies make evident that interactions with lithics are nearly always structured by at least age and gender (Conkey 1991; d'Errico and Banks 2015; Leroi-Gourhan 1964; Roux and Bril 2005; Sellet 1993; Weedman 2002a, b).

Recognition that assemblages may reflect large degrees of practice also presents a problem for approaches grounded in Human Behavioral Ecology and related theories. It is difficult to discern the adaptive value of technologies when datasets also include an indeterminate amount of debris reflecting learning and play. Shea (2006: 214) and Hiscock (2014) recognized that novice waste may make up a large percentage of assemblages going back to the origins of the lithic technology itself (see also Want and Harris 2002). Many analysts are now prioritizing identification of learners in the archaeological record to mitigate the "novice bias" (Cavalli-Sforza and Feldman 1981; Eren et al. 2011; d'Errico and Banks 2015). This has resulted in a growing body of theoretical and methodological approaches for testing hypotheses related to lithic learning (Andrews 2003, 2006; Bamforth and Finlay 2008; Bleed 2008; Finlay 2008; Grimm 2000; Lassen and Williams 2015; Roux et al. 1995; Shelley 1990). 

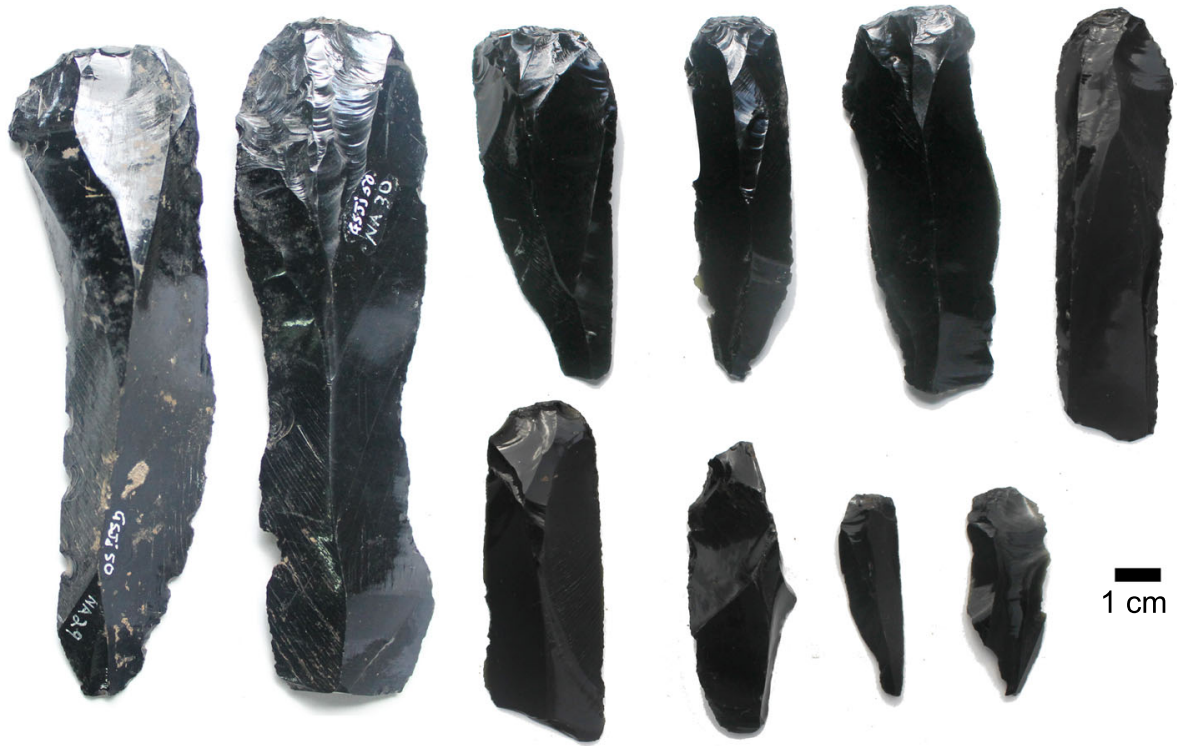

Fig. 2 Typical size and morphological variation in Elmenteitan blades, all samples from the Elmenteitan Obsidian Quarry assemblage

Investigations of learning in the archaeological record are concerned with understanding the process of learning itself, which has significant implications for social structures. Experimental projects aimed at learning often rely on modern, Western, masterapprentice dynamics (Eren et al. 2011, 2015; Stahl 2008). These studies provide invaluable data for quantifying skill and proficiency but might be problematic if directly applied to societies wherein learning does not occur in formal environments (Hayden and Cannon 1984: 331). A number of alternative modes of learning have been outlined by the recent work of d'Errico and Banks (2015) (see all Ferguson 2008). For example, they differentiate between sequential information transfer, where skills have to be acquired inorder, and modular information transfer, where different sets of technical skills can be acquired independently. More importantly is how these skills are transferred. Transmission can be horizontal or vertical between generations (Boyd and Richerson 1985; Cavalli-Sforza and Feldman 1981; Shennan 2002). For example, age-grade models of training (e.g. in herd management, warfare, or ritual knowledge) common among Niloticspeaking herders in East Africa primarily represents horizontal transmission, with learning being a more cooperative act between age cohorts (Tignor 1972). Additionally, some aspects of skill transmission may occur via "scaffolding," where younger learners are directly integrated into the work of older, more skilled individuals (Bamforth and Finlay 2008; Ferguson 2003, 2008; Minar and Crown 2001: 370; Wood et al. 1976).

\section{"Communities-of-Practice" in the Pastoral Neolithic}

The different traditions for passing on knowledge, and the specific settings and strategies of learning, constitute what can be called "communities-of-practice" (Lave and Wenger 1991; Wenger 1998). A communities-of-practice framework provides a means of conceptualizing learning as an ongoing process that can involve diverse and informal 
processes of transmission (Wenger 1998). The concept works nicely to describe a suite of social institutions that may have functioned in similar ways to age-grades, without directly imposing the baggage of such terminology onto the past. Finally, it allows a complex mix of horizontal and vertical knowledge transmission within a single-task group. This flexibility contributes to the growing application of communities-of-practice concepts in archaeology (Creese 2012; Dorland 2017; Holdaway and Allen 2012; Milne 2012; Wendrich 2013). Thinking about learning through this lens provides a more fulfilling vocabulary for how the knowledge and skills surrounding stone acquisition and lithic production may have been passed on by early herders in East Africa.

A critical dimension of defining a community-of-practice is that its members are engaged in a "joint enterprise" or "domain" (Wenger 1998). For Elmenteitan producing communities, we can envision a set of nested domains related to lithic production. Preference for obsidian from Mt. Eburru over other obsidian sources implies that the acquisition of obsidian required its own specialized knowledge "domain." Groups with direct access to the quarry site would have needed to know its location on the upper slopes of the volcanic mountain, how to navigate to it, how to physically quarry obsidian exposures, and the criteria for selecting high-quality obsidians. Novices would have to be taught the specialized set of techniques for blade core preparation that characterize Elmenteitan assemblages (see Goldstein 2018). The community-of-practice using the quarry would also facilitate the transmission of adjacent knowledge about local plant and animal resources, locations of water sources and ochre outcrops, and possibly the procedures for interacting with the hunter-gatherer communities who persisted around Mt. Eburru through the Late Holocene (see Ambrose 1998). In such contexts, the passing on of "practical knowledge" is a venue to impart "knowledgeable practice" (Ingold 1993: 433). Participation builds a set of shared and understood behavioral norms, conditions relationships between individuals, and establishes community membership (Lave and Wenger 1991; Lemonnier 1993: 89; van der Leeuw 1993; Wendrich 2013: 4).

Fortunately for archaeologists, the material remains of communities-of-practice tend to be spatially organized (Holdaway and Allen 2012; Ingold 2010). Grimm (2000: 56) and Porr (2005: 77) have pointed out that role raw-material availability often plays a major role in determining where and how learning take place. It is therefore important to compare evidence for learning and practice from multiple sites. In particular, quarry sites like the Elmenteitan Obsidian Quarry are particularly likely to be places of concentrated learning for lithic production, because it is the only place where highquality raw material was abundant, rather than limited and conserved. If people were traveling to the quarry, or some other location, to participate in communities-of-practice related to lithic production, it might further reinforce the importance of such institutions for maintaining higher order social structures.

\section{Measuring Skill in Lithic Assemblages}

\section{Archaeological Correlates}

Whether we are discussing products of craft specialists or everyday tools, parameters of any lithic tradition must be transmitted to each successive generation (Andrews 2003; Bamforth and Finlay 2008: 9). Depending on the complexity of final products, even 
basic proficiency in a full suite of knapping techniques can take several years of social learning, beginning at a young age (Finlay 1997: 210, 2008: 70; Pigeot 1990; Pelegrin 1990; Stout 2005). The remains of all this practice are captured within the archaeological record, but actually, differentiating between skill levels is challenging. Skill is variably defined but can be considered an individual's technical proficiency in achieving a desired outcome given available means and materials (after Bleed 2008: 156; Roux et al. 1995: 66; Stout 2002: 705). Identification of unskilled knappers therefore relies on identifying artifact morphologies or patterns of production that deviate from an expected norm.

Early archaeological discussions of skill tended to be biased toward recognizing the artisan-level production of bifaces and blades associated with hunting and interpersonal violence (Apel 2008; Flenniken 1978; Whittaker 1987). Certainly highly formal artifacts are indicators of high skill; however, it is problematic to assume that informality and expedience must therefore relate to unskilled knapping. Novices will produce "expedient" tools at a higher rate; however, expedience is itself a technological strategy that can be intentionally employed (Binford 1979; Nelson 1991). Spatial patterns in the distribution of formal versus expedient lithic technologies within a site make for more convincing arguments about the presence of gendered task groups; however, projecting "skill" onto those divisions can be problematic. Archaeological and ethnoarchaeological studies demonstrate the technical complexity of "expedient" methods and are deconstructing simplistic assumptions about gendered or "skilled" divisions of tool use (Arthur 2010; Bamforth and Finlay 2008; Weedman 2002a).

While we can define formal tool attributes related to how much skill a person employed (e.g. fluting on Paleoindian point), it is not always a consistent measure of skill that a person possessed. An ethnographic example is highlighted by Stout (2002: 705) who observed an individual recognized by the Langda community as an expert making novice-like products. Again, the act of production allows individual agency to shape results. This can be hard to recognize archaeologically but must be considered as a possibility when evidence of low-skilled knapping is identified. During ethnoarchaeological work with Gamo hidescrapers in Ethiopia, Weedman (2002a, b) made several observations that are fundamental for thinking about the identification of skill from tools and lithic debris. First, deviations in the formal design of artifacts resulted both from the attempts of unskilled knappers, and from the work of highly knowledgeable, but elderly, experts. Second, she observed that the Gamo hidescraper community-of-practice involved experts helping and guiding novices directly, such that finished artifacts were neither simply the products of only a novice or only an expert.

A second strategy for identifying unskilled knappers in the archaeological record that addresses these complexities is the reconstructing lithic operational sequences, or chaîne opératoire (Grimm 2000; Pelegrin et al. 1988; Julien and Julien 1994). Operational sequences that feature a high degree of production errors or produce cruder forms that are typical for an industry can be attributed to novices, and sequences that exhibit more efficient production with fewer errors can be attributed to experts (Bleed 2008; Eren et al. 2011, 2015; Pelegrin 1990; Pigeot 1990; Stahl 2008). This approach focuses not just on the formal attributes of end-stage products but also considers the ways in which core design and morphology are managed through a reduction sequence (Grimm 2000: 54; Pigeot 1990). Managing core geometry to ensure the production of a particular flake shape requires both skill and knowledge related to maintaining platform 
angles, preparation of platforms, and planning multiple removals or even stages of removals, in advance. Possessing these skills - and the patience to properly employ them-is born from experience, manifesting less often in the knapping efforts of novices or children.

In rare cases, archaeologists have recovered complete or nearly complete refit sequences that appear to reflect instances of learning or novice mimesis of expert production (e.g. Bodu et al. 1990; Dugstad 2010; Takakura 2013). Complete core reduction sequences can be assembled from such refits, allowing archaeologists to identify and track differently skilled individuals through a site. These instances are probably as close as we will get to true proxies for ancient lithic learning. Unfortunately, refit sequences are generally rare in Elmenteitan - and indeed most African Holocene - assemblages, as sites often manifest as undifferentiated middens or secondary deposits, often disturbed by trampling or other post-depositional mixing (e.g. Gifford et al. 1980; Lane et al. 2007; Robertshaw 1990, 1991). It is still possible to discuss lithic learning and skill in such instances; however, this requires less ideal approaches that consider aggregate flake assemblages. Production mistakes are the one enduring characteristic of unskilled knapping revealed in experimental and archaeological studies, and these can be evaluated on a flake-by-flake basis (Högberg 2008; Pigeot 1990).

\section{Production Errors in Lithic Assemblages}

Typical production mistakes include step and hinge terminations, overshot flakes, split cores, and flakes with aberrant morphologies (Clark 2003; Crabtree 1972; Eren et al. 2015). Such mistakes are usually the result from a failure to properly prepare the striking platform, a misapplication of force, failing to reset blade release surfaces, or failing to correct previous mistakes (Finlay 2008: 81). Even if flakes are successfully struck, some aspects of improper preparation leave visible features that can be used to infer skill level. Either due to inexperience or lack of physical strength or dexterity, novices tend to be less able to problem solve and remove such mistakes, and so accumulations of multiple step fractures or multiple misstrikes from unprepared platforms are stronger indicators of low skill (Andrews 2003; Finlay 2008: 87; Milne 2012; Roux and David 2005). There is also speculation that novices are trained with lowerquality materials. Identification of differential core chaîne opératoire between raw material types or qualities serves as an additional line of evidence for novices (Ferguson 2003, 2008).

Standardization, the consistency in form of end products, is also considered to be a measure of skill in lithic production (Costin and Hagstrum 1995; Eerkens 2000; Eerkens and Bettinger 2001). This might be applicable for the Elmenteitan, wherein cores were designed to produce consistently long blades with low curvature (Ambrose 1984a, 2001; Goldstein 2018; Nelson 1980). High skilled reduction sequences should show lower variability in morphology and attributes, whereas novice knapping is likely to produce a wide range of flake shapes and a higher proportion of flakes that do not fit the "intended" form. Deviations in blade shape and form can therefore also be considered a type of production error.

Production errors are inevitable even for experts; however, a critical dimension of knapping skill is the ability to correct for mistakes. Therefore, evaluations of skill based 
on error identification can reasonably weight evidence for repetitive mistakes like stacked step fractures around a platform differently from flakes oriented to remove errors or otherwise solve problems. A final important consideration is that any criteria for defining mistakes or deviations in operation sequence must be rooted in a firm grasp of the technological parameters of the focal lithic industry. Eren et al.'s (2013) conclusion that overshot flaking in Paleolithic and Paleoindian biface assemblages were production mistakes would lead to very different interpretations than would assertions that this was a high-skill biface thinning method (Bradley and Stanford 2004). Expectations for one industry cannot always be simply transplanted onto another.

\section{Expectations for the Elmenteitan}

The Elmenteitan Obsidian Quarry is the best candidate site for a center where communities-of-practice focused on lithic learning might be focused. In places of raw material abundance, mistakes have little material cost. Quarry assemblages should exhibit a higher frequency of mistakes with or without a learning component to site use. This trend is referred to by Clark (2003) as the "Brandon Bias," qualitatively established for quarries where people were preparing bifaces. While obsidian is abundant at the Elmenteitan Obsidian Quarry, blocks of high-quality glass are usually encased in lower-quality material riddled with flaws and inclusions (Goldstein and Munyiri 2017). Having to invest significant effort in testing nodules and removing the outer material to find suitable nodules would cause people to take more care in core preparation. There is thus also an incentive to "show off" when the social setting of knapping involves a higher ratio of peers, which might work against a "Brandon Bias" effect. Ethnographic observations by Stout (2002: 334) demonstrate that successful removals can be a source of pleasure and pride for the producer. If debris and core modifications reflect counter-productive design and reduction, it may be assumed that these reflect an issue of skill rather than haphazard knapping.

An initial hypothesis is that error rates should be highest at the quarry site relative to other Elmenteitan sites due to it being an advantageous location for learning to occur and/or due to the Brandon Bias. If this expectation is falsified, it might indicate a higher proportion of experts at the quarry and that Elmenteitan communities-of-practice surrounding transmission of knapping skills was differentially organized on the landscape. Whatever the distribution of blade error rates is among sampled Elmenteitan sites, it allows for some level of insight into the social organization of early African herders. Based on previous analyses, we can assume that the mechanism for obsidian acquisition is an informal exchange network (Ambrose 2001; Goldstein and Munyiri 2017; Robertshaw 1990).

A second testable hypothesis is that error rates and error types should be patterned relative to the blade size. Elmenteitan groups produced primarily single platform blade cores, and so, ceteris paribus, longer blades can be assumed to come from large earlierstage cores and shorter blades derived from later-stage core. Producing longer blades is generally more difficult, requiring more careful consideration of where blades are to be struck, more careful preparation, greater support along the release surface, and precise application of force. At a quarry site, there may be reduced effort even by skilled individuals during the very earliest phases of blade reduction before the cores are fully prepared for transport. As reduction continues and cores reach the size at which they 
are to be "exported" to Elmenteitan habitation sites, time and energy investment should increase to prevent major production errors. Based on maximum blade lengths at Elmenteitan sites, cores are likely finalized at maximum lengths around $12 \mathrm{~cm}$ (Ambrose 1980; Goldstein 2014: 12). If skilled individuals are producing cores, error rates on blades should decrease before this point, as cores become smaller and blade production becomes less error prone. If novices are present at the quarry, error rates may still gradually decline with decreasing blade length, but will remain higher than either the "variable" effort model of experts discussed above, or a scenario in which experts were applying maximum effort throughout all stages of production (Fig. 3). Comparing the distribution of obsidian blade errors through the reduction sequence at the Elmenteitan Obsidian Quarry will provide clues as to which, or how many, of these patterns is present and thus the composition of communities-of-practice at the site.

\section{Methods}

\section{Quantifying Error Rates}

To evaluate the possibility of learning and hypotheses regarding the nature of communities-of-practice within the Elmenteitan, I quantified the error rates in the blade assemblages of seven Elmenteitan sites (discussed below). I selected only blades that were complete, including those with languette, step, or hinge terminations. Fragmentary debitage was not included, as it is often difficult to distinguish accidental production snaps from either intentional blade segmentation or snaps from trampling, and

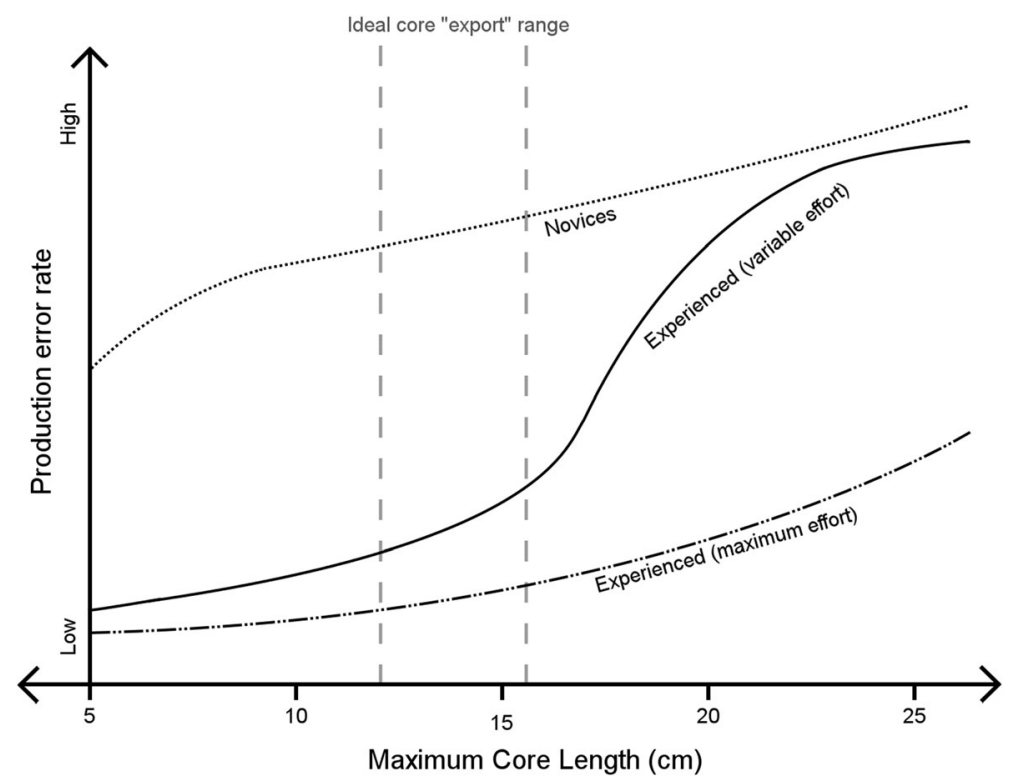

Fig. 3 Expected patterning of error rates through the reduction process for novices versus experienced knappers for Elmenteitan assemblages. Ideal export range is the size range at which prepared obsidian cores appear to enter habitation site assemblages 
complete blades are required to evaluate the full range of attributes and measures that would reflect deviations from the intended morphology.

I created a list of measurable attributes related to both "high skill" and "low skill" blade reduction following criteria established through the archaeological and experimental projects of Bamforth and Finlay (2008), Ferguson (2003), Eren et al. (2011), Lassen and Williams (2015), Milne (2012), and Tostevin (2013) (see Table 1) and include several traditional "mistakes," including double bulbs of percussion, step and hinge terminations, dorsal steps or hinges, and high curvature.

Additional criteria were added to account for the specific nature of Elmenteitan blade industries based on the following assumptions: (1) blade production is intended to produce blanks of consistent size and shape; (2) blades with length:width or length:thickness ratios that are too high or low would be undesirable; (3) while mistakes are inevitable, repeated mistakes are a sign of novices and corrected mistakes are a sign of experts; (4) over- and underprepared platforms are a sign of novices (Fig. 4). The first category is that of "initiation errors" relating to damage to the striking platform originating from the misapplication of force. Shattered platforms or incidences where the bulb of percussion was sheered from the blade (most likely from obtuse angling of the punch relative to the platform angle) were the most typical forms of initiation errors. Double or triple bulbs of percussion and battering on the striking platform are also signs of inexperienced knapping and so are counted as errors. It is possible to consider under- and overpreparation of a striking platform as signs of novice knapping. Aside from platforms that have no preparation, this measure becomes increasingly subjective, and so, these variables were recorded but not counted in error calculations for this study.

The second category is "termination errors". By removing a portion of the core base, each plunging termination makes the core shorter, reducing the maximum potential blade length of the succeeding removals. For this reason, it is viewed as an undesirable error. More obvious mistakes come in the form of hinge terminations that create a problem on the core face that impede subsequent removals. Languette fractures are also

Table 1 Characteristics of skilled and unskilled knapping in blade-based lithic assemblages. Modified for Elmenteitan blade production from Bamforth and Finlay (2008)

\begin{tabular}{ll}
\hline Indicators of high levels of skill & Indicators of unskilled knapping \\
\hline Very large blade size & Irregularity in form \\
Very low thickness-to-width ratio & Predictable errors \\
Extreme length relative to width or thickness & Stacked step and hinge terminations \\
Regularity of form & Inconsistency in production \\
Plan view symmetry & Plan view asymmetry \\
Very small platform-to-size ratio & Low length-to-width or length-to-thickness ratio \\
Complex, patterned, multi-stage reduction strategies & Deviation from expected châine opératoire \\
Maintenance of core shape through reduction & Peripheral knapping location \\
& Failure to maintain, properly prepare, or rejuvenate \\
& platforms \\
& Overprepared platforms
\end{tabular}



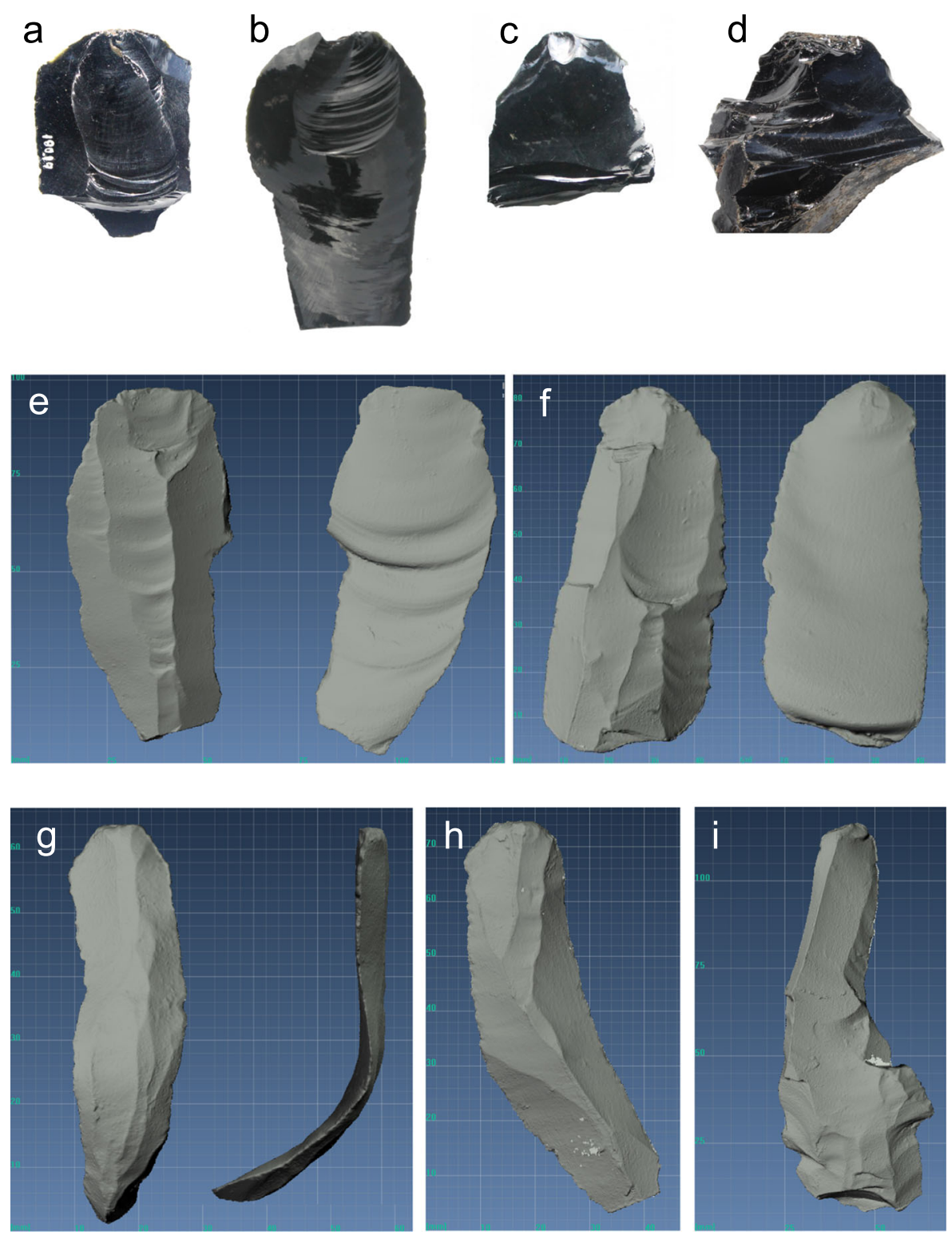

Fig. 4 Examples of blade production errors defined in this study. a "Sheered" bulb with languette fracture. b, e Bulb/platform shattered. c Platform damage and languette break. d Stacked step fractures and platform crushing. f Multiple dorsal step fractures and hinge termination. $\mathbf{g}$ High curvature. $\mathbf{h}$ Lateral skew. i Blade that "corrects" opposed dorsal step fractures. Examples from Elmenteitan Obsidian Quarry (a-d), Remnant Site (e, f), Enkapune Ya Muto (g, h), and Ngamuriak (i). 3D scans generated using AICON SmartScan and OPTOSCAN

typically seen as a blade production errors (Lenoir 1975). These were recorded but were not included in quantitative analyses due to difficulties distinguishing them from intentionally segmentation and post-depositional trampling. Evidence of previous step or hinge fractures on the dorsal surface of a blade also counted as errors. To avoid 
double-counting a dorsal hinge and the hinge termination from another sampled blade, I only counted dorsal fractures near the proximal end.

Finally, flake morphologies that fail to achieve the desired shape can also constitute an error by a knapper. Elmenteitan core morphologies and blade reduction strategies are designed to produce long, flat, and straight blades (see Ambrose 2001; Goldstein 2018) and so high proximal-distal curvatures (calculated following Andrefsky (2016)) or lateral skews of over $30^{\circ}$ were counted as production errors. This category of error also includes blades with metric ratios over two standard deviations from the assemblage mean as being mistakes as they would be too thin or too thick to be ideal for tool production.

Each individual production error was given a score of " 1 ," and the cumulative error score for a blade was calculated as the sum of all categories where an error was present. Blades that successfully removed previous dorsal steps or hinges, from an opposed end or adjacent edge of the core (e.g. Figure 4i, see also Goldstein 2018; Fig. 5), indicate a skilled correction of a mistake and were given a score of "- 1 ," and the presence of stacked uni-directional step fractures or step fractures in association with platform "batterning" were given a score of "2" (Table 2). I did this in order to account for skilled correction of mistakes versus unskilled repetition of mistakes. I calculated error rates for each assemblage as the average error score of all complete blades sampled from that site.

As an evaluation of the method itself, it is important to determine if there are strong correlations between any two types of errors. If the physical mechanics responsible for something like platform shattering is associated with hinge terminations, then the method would be double counting a single production error. If types of production
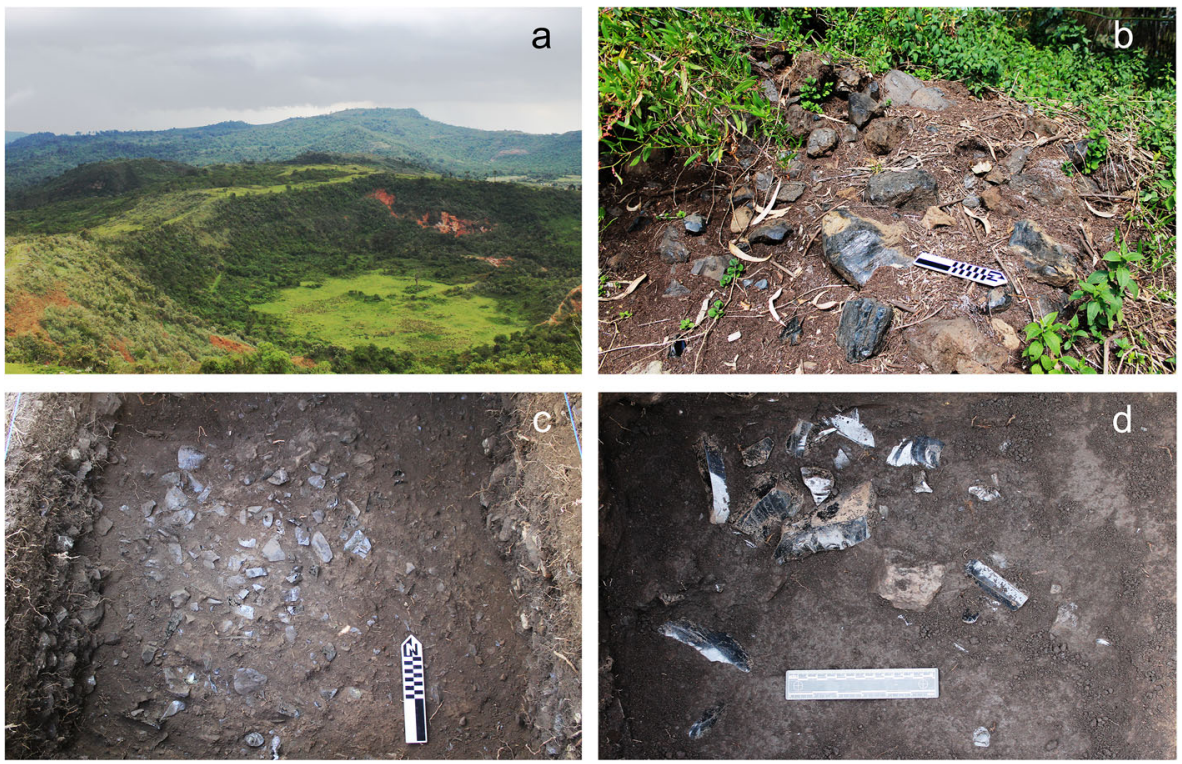

Fig. 5 The Elmenteitan Obsidian Quarry on Mt. Eburru. a The setting of the quarry site on the upper slopes of Mt. Eburru. b "Spoil" pile of low-quality obsidian and mixed core testing debris at the quarry. c Dense accumulations of core preparation debris in the central quarry area. d Example of a blade cluster with mixed fauna and ceramic in the area surrounding the central quarrying area 
Table 2 Criteria for scoring production errors on Elmenteitan blades

\begin{tabular}{|c|c|c|}
\hline Variable & Criteria & Error score \\
\hline Bulb/platform errors & $\begin{array}{l}\text { - Shattered platform; } \\
\text { - "Battered" platform; } \\
\text { - Sheered or damaged bulb of percussion; } \\
\text { - Double or triple bulb of percussion }\end{array}$ & 1 each \\
\hline Termination errors & $\begin{array}{l}\text { - Hinge terminations; } \\
\text { - Remnant hinge or step features on } \\
\text { dorsal side }\end{array}$ & $\begin{array}{l}1 \text { for single errors } \\
2 \text { for } 2-5 \text { errors, compounded step } \\
\text { fractures } \\
-1 \text { for evidence of corrected errors }\end{array}$ \\
\hline Blade asymmetry & $\begin{array}{l}\text { - Lateral skew }>30^{\circ} \text {; } \\
\text { - Significant blade twist; } \\
\text { - Curvature over } 2 \text { s.d. from sample mean }\end{array}$ & 1 each \\
\hline Size/shape & $\begin{array}{l}\text { - Length:width or length:thickness ratio } \\
\text { over/under } 2 \text { s.d. from sample mean }\end{array}$ & 1 each \\
\hline Recorded, not scored & $\begin{array}{l}\text { - Intensity of platform preparation } \\
\text { - Languette terminations }\end{array}$ & \\
\hline
\end{tabular}

errors are not correlated, then it becomes useful to also consider the types of production errors that appear most often and the ratio between blades with single versus multiple production errors. Finally, I recorded other variables that might be relevant for understanding how and why errors appear, and how they are distributed within a reduction sequence. This includes the nature of striking platforms (prepared with the standard dorsal-proximal grinding of Elmenteitan blades (Ambrose 2001, 2002), overprepared with intensive grinding, or unprepared), and maximum blade length as a correlate for the size of the core at the time of removal.

\section{Sampled Sites}

I calculated error rates for blade assemblages from eight Elmenteitan sites: the Elmenteitan Obsidian Quarry, Enkapune Ya Muto, Gogo Falls, Ngamuriak, Njoro River Cave, Olopilukunya, the Remnant Site, and Wadh Lang'o. These sites were chosen because they are the best published Elmenteitan occurrences with the largest available blade assemblages available for comparative analysis. Obsidian is the dominant raw material at all sites and the only material that was used for formal blade core reduction. Only complete obsidian flakes that could reasonably be assigned to a blade core reductions sequence (i.e. possessing parallel flake scars indicative of serial removals from a hierarchical core) were selected for this study. Alternative criteria exist for defining blades; however, metric- or attribute-based definitions might exclude aberrant morphologies that might be relevant for measuring error rates and evaluating skill in an assemblage.

The sampled sites are also distributed across a wide range of ecological zones. They also cover the Elmenteitan temporal sequence. Fortunately, there is little evidence for technological change through the Elmenteitan. A related limitation is that the available blade assemblages are small, although results are adequate to achieve statistical significance through re-sampling procedures (in this case, bootstrapping resampling 
protocols were employed for all statistical tests). Small sample sizes are a pervasive problem in Pastoral Neolithic archaeology due to both limited excavations and the ephemeral nature of early herding sites. Conclusions derived from the study should be considered cautious hypotheses in need of further testing with new, larger assemblages. Using sites as the unit of analysis can be problematic in that some sites are palimpsests of several episodes of lithic reduction, possibly spanning several hundred years. Sampled Elmenteitan sites show varying evidence for this effect, which is noted for each site below. To mitigate this problem, I attempted to sample from specific dated contexts or horizons that most likely reflect a shorter depositional timespan. Ultimately, the analyses here are presented as preliminary case study with larger scale excavations of PN sites being necessary to apply the method on an intra-site scale.

The final sampling issue is that blades with significant production mistakes are more likely to be abandoned in archaeological assemblages than are less problematic blades, which are more likely to be selected for tool production. This form of selection bias may result in an overrepresentation of mistakes within an assemblage as recovered archaeologically, but from a comparative perspective, we must assume that all sites (besides the quarry) exhibit that bias to the same degree. Specific details of the sampled sites are given below and summarized in Table 3.

The Elmenteitan Obsidian Quarry (GsJj50) The Elmenteitan Obsidian Quarry is the largest documented source of the geochemically distinct green-hued obsidian that makes up upwards of $90 \%$ of the total lithic raw material at nearly all Elmenteitan sites. The quarry is located on the upper slopes of Mt. Eburru, a volcanic complex that extends from the Mau Escarpment just north of Lake Naivasha (Fig. 5). The site was first identified by Stanley Ambrose in 1980, and was first excavated in 2014 (Goldstein and Munyiri 2017). Unlike most archaeological quarries, there is little surface material at the Elmenteitan Obsidian Quarry other than what has been exposed in road cuts or in recent hand-tilled agricultural fields. Volcanic soils and high rainfall appear to have

Table 3 Sites used in comparative analysis, with dates, distance from quarry, blade sample size, and average blade length

\begin{tabular}{|c|c|c|c|c|c|c|}
\hline Site & Abbreviation & $\begin{array}{l}\text { Date range } \\
(\text { cal. BP })^{\mathrm{a}}\end{array}$ & $\begin{array}{l}\text { Distance from } \\
\text { quarry }(\mathrm{km})^{\mathrm{b}}\end{array}$ & $n$ & $\begin{array}{l}\text { Blade length } \\
(\mathrm{mm})\left[\bar{x}, \sigma_{x}\right]\end{array}$ & Reference \\
\hline $\begin{array}{l}\text { Elmenteitan } \\
\text { Obsidian Quarry }\end{array}$ & EOQ & 2160-1996 & 0 & 583 & $55.59,24.47$ & $\begin{array}{l}\text { Goldstein and } \\
\text { Munyiri } 2017\end{array}$ \\
\hline Enkapune Ya Muto & EYM & 3071-1932 & 25 & 43 & $70.63,16.77$ & Ambrose 1984a \\
\hline The Remnant Site & REM & $2730-1935$ & 27 & 29 & $61.43,15.97$ & Nelson 1980 \\
\hline Njoro River Cave & NJR & $3206-2787$ & 50 & 23 & $59.6,16.79$ & $\begin{array}{l}\text { Leakey and } \\
\text { Leakey } 1950\end{array}$ \\
\hline Ngamuriak & NGA & $2301-1528$ & 100 & 56 & $64.21,26.63$ & Robertshaw 1990 \\
\hline Olopilukunya & OLI & 2677-2094 & 130 & 20 & $45.30,14.06$ & Robertshaw 1990 \\
\hline Wadh Lang'o & WDL & $1806-1543$ & 170 & 26 & $51.21,14.35$ & Lane et al. 2007 \\
\hline Gogo Falls & GGF & $1992-1610$ & 210 & 35 & $48.78,11.72$ & Robertshaw 1991 \\
\hline
\end{tabular}

\footnotetext{
${ }^{\text {a }}$ Age range is $2 \sigma$, calibrated using OxCal 4.2 with SHCAL13 Curve (Hogg et al. 2013)

${ }^{\mathrm{b}}$ Approximate straight line measurement
} 
fueled rapid soil development, and so, most of the archaeological horizon is found 30$60 \mathrm{~cm}$ below the surface. As a result, it is only possible to obtain large samples through excavation, and so, the available sample size is much smaller than might be expected for quarries with large surface exposures.

Excavations revealed an archaeological horizon of dense lithic debris, largely related to core preparation and blade reduction. In discrete areas surrounding the central quarry deposit, lithics were comingled with ceramics, fauna, ochre, and charcoal. Surveys of the surrounding area failed to detect significant open-air Elmenteitan habitations, and there is no source of permanent potable water on the upper slopes of Eburru. Discrete patches of habitation debris at the quarry are suggested to be the remnants of "camps" from small groups engaged in episodic obsidian quarrying. The sample used in this analysis comes from two $1 \times 2-\mathrm{m}$ trenches placed within one such cluster and a $1 \times 1-\mathrm{m}$ excavation unit in the central quarry deposit. Radiocarbon dates from the top and bottom of the archaeological horizon suggest rapid deposition in the camp area from 2160 to 1996 BP (Goldstein and Munyiri 2017 [OS-12282-3]).

While there is significant evidence of early-stage debris at the site, most of the assemblage reflects the normal range of blade reduction, down to exhaustion of bladelet cores. Excavations produced a total of 583 blades made on obsidians that ranged from low- to high-quality glass, whereas only the nearly pure glass is found at other Elmenetitan habitation sites. This presents an opportunity to examine expectations that novices will be preferentially given low-quality material for practice, as proposed by Ferguson (2003, 2008) and Högberg (2008).

Enkapune Ya Muto Enkapune Ya Muto is a 7 by $11 \mathrm{~m}$ rock-shelter site situated along the steep eastern slopes of the Mau Escarpment, $2400 \mathrm{~m}$ above sea level. It is the closest sample in this study to the obsidian sources and quarry site used by Elmenteitan groups. Excavations by Stanley Ambrose in 1982 revealed a deep sequence that extends from the Middle Stone Age to the Pastoral Iron Age (Ambrose 1984a; 1998). Elmenteitan strata dating to 2600 BP produced a dense lithic assemblage with wild and domesticated fauna (Ambrose 1984a, 1998). A total of 43 complete blades from the dated Elmenteitan horizon were sampled for comparative analysis. Despite secure dating, the complex taphonomic conditions in the rock-shelter introduce the most potential that the sampled blades were manufactured across multiple knapping episodes.

Gogo Falls Located on the eastern shores of Lake Victoria, Gogo Falls is the westernmost Elmenteitan occurrence and the furthest from the Mount Eburru obsidian source. It is a stratified multi-component site with significant Kansyore fisher-forager deposits underlying the Elmenteitan stratum, which in turn are overlaid by Iron Age levels (Robertshaw 1991; Wandibba 1986). Significant excavations were carried out by Robertshaw and Karenga-Munene between 1983 and 1989, covering over $160 \mathrm{~m}^{2}$. (Robertshaw 1991). Layers with characteristic Elmenteitan lithics and ceramics, along with domesticated fauna, were dated to between 1992 and 1610 BP. Green-hued obsidians with geochemical signatures uniquely found on Mt. Eburru are the most dominant obsidian type (in all Elmenteitan contexts across excavation areas between 70 and 100\%) (Robertshaw 1991: 87). The sample from Gogo Falls consists of 35 blades from the dated Elmenteitan horizons in Trench II. 
Ngamuriak Ngamuriak is a large Elmenteitan settlement site in the Lemek Valley along the Oldorotua River in the Loita-Mara region of southwestern Kenya. It was first identified in a large erosional feature that revealed an otherwise undisturbed $20-30 \mathrm{~cm}$ archaeological horizon. There were three seasons of excavation by Fiona Marshall and Peter Robertshaw between 1981 and 1985, covering roughly $1094 \mathrm{~m}^{2}$. (Robertshaw 1990: 54). Radiocarbon dates for the archaeological horizon largely cluster around 2000 BP. A total of 22,738 lithic artifacts were recovered, and $85 \%$ of specimens analyzed during geochemical sourcing were identified as green obsidians sourced to Mt. Eburru (Merrick et al. 1990; Robertshaw 1990: 88). A total of 56 blades from the midden horizon in the main excavation area at Ngamuriak were sampled for comparative analysis. The radiocarbon dates suggest a single phase of site use, although without more comprehensive dating, it remains possible that even the central midden was generated from multiple occupations.

Njoro River Cave Excavated by Louis and Mary Leakey (1950), Njoro River Cave is a dense mortuary site located along the banks of the Njoro River, a few kilometers west of Lake Nakuru. The Leakeys excavated roughly $140 \mathrm{~m}^{3}$ of the outer rock-shelter area to a depths of between 1 and $2.7 \mathrm{~m}$ after observing human remains and stone bowls on the surface (Leakey and Leakey 1950: 2). It was revealed to be a dense burial ground with the remains of over 80 individuals. Njoro River Cave was sampled for two reasons. First, it is the earliest dated occurrence of the Elmenteitan assemblage group to 3206-2787 BP (2900 uncal. BP) (Merrick and Mohanagan 2010). It is also primarily a mortuary site, possibly representing different social circumstances and production strategies than habitation site. Njoro River Cave is the only site where the tool assemblage lacks a high proportion of scrapers or burins (although a few are present). Microlithic and informal tools resemble other Elmenteitan sites. There are 23 complete blades in the assemblage from Njoro River Cave that were included in the comparative analysis. Sediments in the cave were highly mixed from repeated mortuary activities, and so, this assemblage is the most problematic and likely to reflect multiple knapping episodes. It is included as the only assemblage from a ritual Elmenteitan site.

Olopilukunya Olopilukunya is an open-air settlement site located near the western edge of the Loita Hills. The site itself is situated near a seasonal stream within open grassland (Robertshaw 1990: 268). Charles Cable directed excavations of the site in 1985, which covered a total of $33.5 \mathrm{~m}^{2}$. Excavators noted that archaeological materials were restricted to a $5-10-\mathrm{cm}$ horizon, leading to the assertion that was at least a single phase, if not a single archaeological occupation (Robertshaw 1990: 269). Ceramics and lithics are typical of the Elmenteitan, and the fauna was almost entirely domesticated (Robertshaw 1990: 272). The entire technological package has numerous similarities to those noted for the Elmenteitan of the Lemek Valley and Central Rift. Due to the thin occupational horizon and limited excavation, the 22 sampled blades reflect the entire blade assemblage from the site.

The Remnant Site The Remnant Site is located at an elevation of over $2800 \mathrm{~m}$ above sea level on the Mau Escarpment and was excavated by C. M. Nelson, J. R. F. Bower, A. F. Waibel, and S. Wandibba between 1975 and 1976. The site was identified as a single occupation with one uniform archaeological horizon 40 to $60 \mathrm{~cm}$ below surface, 
dating to $2315 \pm 150$ (Bower et al. 1977: 131). Lithic material from the two $2 \times 2 \mathrm{~m}$ excavation units was clustered such that it might represent a single knapping episode. I sampled 29 blades from the Remnant lithic assemblage.

Wadh Lang'o Wadh Lang'o is a multi-component site with early Holocene Kansyore, Elmenteitan, and Iron Age Urewe materials similar to those at Gogo Falls, also located along the eastern shore of Lake Victoria. Frederick Odede and Isaya Onjana supervised initial excavations between 1991 and 2001, and Ceri Ashley supervised another series of excavations in 2004 (Lane et al. 2007). Excavations covered, in total, $47 \mathrm{~m}^{2}$. of the site. A series of charcoal radiocarbon dates span the last 3300 years, with the Elmenteitan horizon dating to between 1532 and 1806 BP. Like Gogo Falls, deposits of Wadh Lang'o demonstrate a rapid shift toward obsidian-dominated lithic technologies within the PN layers relative to previous Kansyore deposits (Lane et al. 2007). Lane et al. (2007: 66) argue for stronger stratigraphic integrity at Wadh Lang'o; however, they note that in some excavation units, it was clear that Elmenteitan and Urewe materials were somewhat mixed. In order to limit the inclusion of postElmenteitan lithic material as much as possible, I predominantly sampled the more secure lower Elmenteitan strata. I did choose to include blades from other contexts where associated tools were morphologically Elmenteitan. In total, I was able to sample 26 blades from the dated Elmenteitan layers.

\section{Results}

\section{Error Patterns at the EImenteitan Obsidian Quarry}

Excavations at the Elmenteitan Obsidian Quarry have produced the largest available obsidian blade assemblage for southern Kenya, and this is the only assemblage where the entire reduction sequence from nodules to small blades is well represented. As a result, it is the best sample for assessing whether there are any correlations between the identified error types that might bias error rate calculations. It also presents an opportunity to assess how error rates correlate with blade size, which itself is a good proxy for the stage of core reduction within the Elmenteitan (Goldstein 2018). Furthermore, raw material ubiquity at the site, its physical location on the forest peak of Mt. Eburru isolated from Elmenteitan habitation zones, and its economic importance for supplying a regional exchange network make it a location where we would strongly expect to find evidence of lithic learning.

In total, $44 \%$ of the blades from the Elmenteitan Obsidian Quarry exhibited at least a single production error. Only $11 \%$ of the total sample had multiple production errors. Of those with multiple errors, nearly a quarter of these $(n=31)$ have an error score of " 3 " and only $4 \%(n=6)$ had an error score of " 4 ." Thirteen blades ( $1 \%$ of the total assemblage) had a single error that had been corrected such that they were given an error score of "- 1 ." Termination errors constitute a large majority of these, with $18 \%$ of the sample having a plunging termination that removes a large portion of the opposing end of the core and $27 \%$ having a hinge termination. If languette snaps $(n=120)$ were included, they would account for $18 \%$ of all errors that occurred at the moment of blade 
removal, raising the total percentage of the sample with any errors to $62 \%$. Hinge or step fractures on the dorsal surface of a blade were the next most common form of error counted, making up for about $20 \%$ of the production errors in the assemblage. Only $12.5 \%$ of the blades had errors relating to the striking platform. Unlike termination errors that negatively affect both the parent core and blade product, striking platform errors are almost all either crushed platforms or bulbar sheering reflecting misalignment of an indirect precursor and do not appear to have otherwise negatively impacted the blade. Only around $1 \%$ of the blades had very high curvatures, lateral skews, or deviated significantly in their length:thickness ratios.

Analysis of error frequency and average error values consistently show an increase in error rates through the reduction sequence such that the smallest blades have higher rates of errors. Blade length has the most nuanced pattern, with a spike in error rates occurring at lengths of $7.5-8 \mathrm{~cm}$, with a consistently higher error rate setting in after $6 \mathrm{~cm}$ (Fig. 6). Each individual variable involved in calculating error rates, such as termination errors, platform damage, or remnant dorsal hinge or step scars, follow the same pattern with the highest rates from 6 to $4 \mathrm{~cm}$ blade lengths. There is very little evidence that any individual error rates correlate with one another. The only variable that may be an exception is curvature with the flatter and straighter blades exhibiting more errors.

A few attributes that were recorded but which did not contribute to error scores do show more substantial relationships with error rates and error scores. Surprisingly, there was no difference in error rates between unprepared and prepared platforms; however, platforms that were qualitatively described as "overprepared" relative to the rest of the assemblage were $10 \%$ more likely to have a production error (Supplemental Fig. 1). Additionally, there is a possible correlation between skill and blade length:thickness ratios. The highest "skill" blades - those which are the longest and thinnest - have the

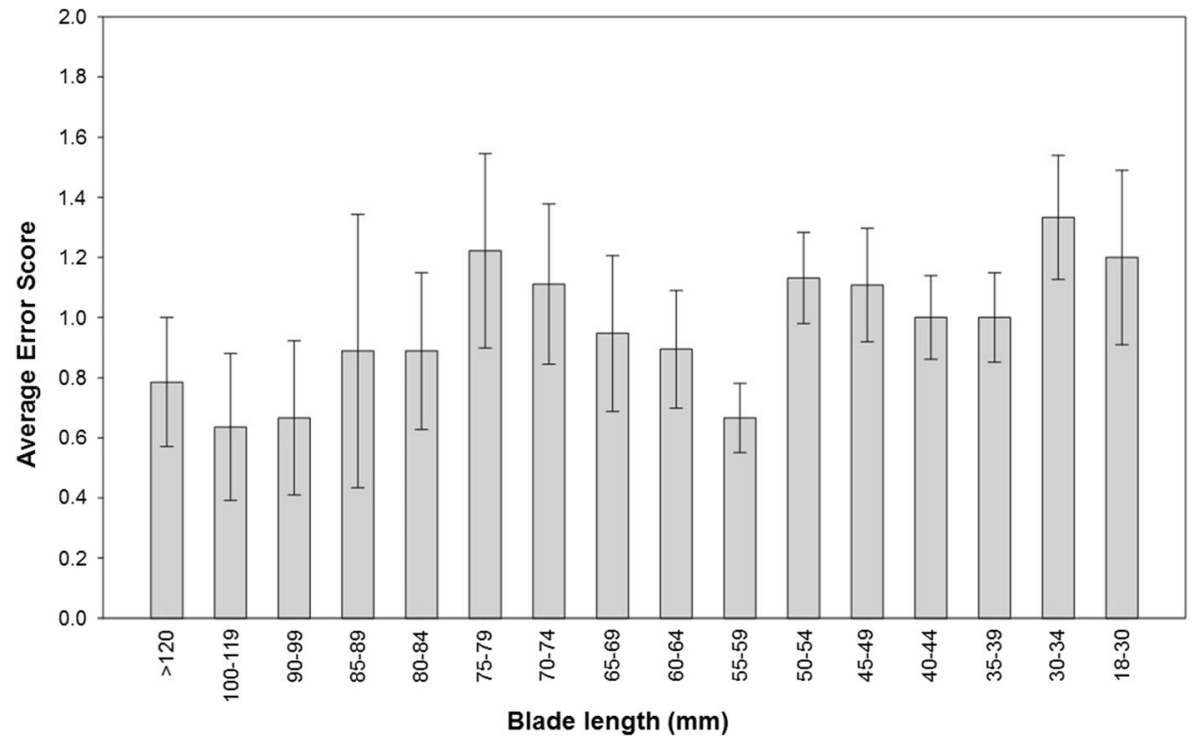

Fig. 6 Average production error scores with standard error through the core reduction sequence (based on blade length) based on blades from the Elmenteitan Obsidian Quarry 
lowest rates of errors (Supplemental Fig. 2). As blades become thicker and/or shorter, error rates gradually increase $\left(\chi^{2}=13.28, \mathrm{df}=6, p=.039\right)$. There is no correlation between blade striking platform size when controlling for blade length, and there is no difference in the frequency of error rates among blades made from high- or low-quality obsidian $\left(\chi^{2}=6.68, \mathrm{df}=6, p=.347\right)$. Interestingly, the lower quality obsidian blades have a higher rate of "repair" blades that remove previous errors, resulting in somewhat lower average error scores.

\section{Comparative Error Rates}

Blade production error rates were also assessed for assemblages from seven additional Elmenteitan sites to determine what, if any, variation in the frequency or types of error rates there was across southwestern Kenya (Fig. 7, Table 4). These assemblages, though much smaller, reflected the same general relationships between error rates and morphologies that were observed for the comprehensive quarry site assemblage. Like the Elmenteitan Obsidian Quarry dataset, none of the comparative assemblages has evidence for positive correlations between any of the features that were counted as errors in this analysis.

The proportion of obsidian blades with some form of error varied widely among the sampled assemblages, ranging from 28\% (Olopilukunya) and 84\% (Njoro River Cave). As expected, the Elmenteitan Obsidian Quarry has a relatively high rate of blades with errors (45\%), but both the Remnant Site and the mortuary site of Njoro River Cave exhibited average error scores that are at least equivalent, if not greater. The two openair sites in the Lemek-Mara region highlands (Ngamuriak and Olopilukunya) have much lower error rates by comparison. Wadh Lang'o and Gogo Falls, both near Lake Victoria on the westernmost extent of the Elmenteitan distribution, show similar midrange error rates. Site type and function appear to have little correlation with the

$1.50-$

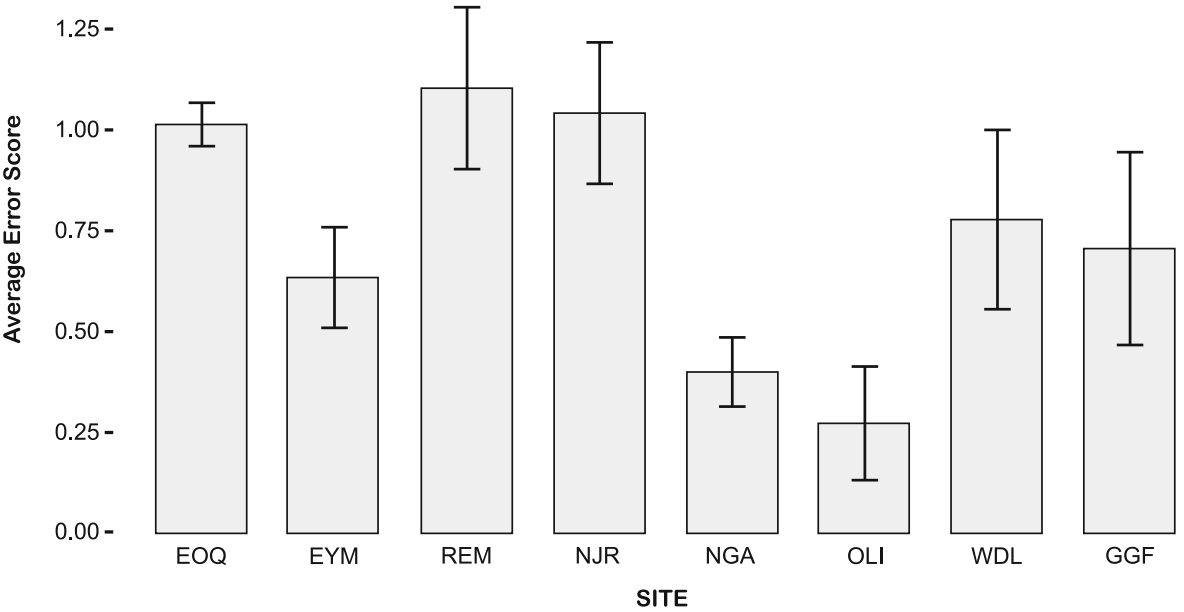

Fig. 7 Average error scores for the sampled Elmenteitan obsidian blade assemblages. Error bars represent standard error. Sites are arranged left-to-right by the distance from the Mt. Eburru obsidian source 
Table 4 Summary table of blade production error types and average error scores for sampled Elmenteitan assemblages

\begin{tabular}{lllllll}
\hline Site & $n$ & Dorsal fracture & Termination & Initiation & Morphology & $\begin{array}{l}\text { Average } \\
\text { error score }\end{array}$ \\
\hline EOQ & 583 & 113 & 347 & 70 & 5 & 0.982818 \\
EYM & 43 & 3 & 14 & 6 & 2 & 0.634146 \\
REM & 29 & 12 & 12 & 2 & 1 & 1.172414 \\
NJR & 23 & 4 & 9 & 5 & 4 & 1.166667 \\
NGA & 56 & 7 & 7 & 5 & 2 & 0.4 \\
OLI & 20 & 0 & 1 & 1 & 1 & 0.272727 \\
WDL & 26 & 6 & 4 & 3 & 1 & 0.944444 \\
GGF & 35 & 5 & 4 & 4 & 1 & 0.823529 \\
\hline
\end{tabular}

frequency of blade production mistakes as measured here. The relationship between error rate and distance from Mt. Eburru are also not straightforward; however, there appears consistently higher average error rates for sites closer to the Elmenteitan Obsidian Quarry. Higher average error rates at the sites nearer to the quarry are caused by the greater frequency of errors on smaller blades in these assemblages. Longer and flatter blades in all assemblages continue to show the lowest rate of errors $\left(\chi^{2}=13.28\right.$, $\mathrm{df}=6$, Monte Carlo $p=.039)$. Inverse correlations between length and error rates may also explain why there are higher error scores at the most distant sites of Wadh Lang'o and Gogo Falls, where blades are generally smaller. Blade length (i.e. core size) appears to be an important variable to consider in explaining error rates; however, this alone cannot explain all inter-site differences.

Most blade assemblages are consistent in the percentage of blades that have a single classified production error $(\sim 30-35 \%)$. It is the proportion of blades with multiple errors driving variation in averaged error scores (Fig. 8). High error scores at Njoro River Cave and the Remnant Site result from 45 to $50 \%$ of blades in these assemblages have two or more production errors. Proportions of error types also vary considerably between sites (Fig. 9). The rate of blades that are either very thin or very thick relative to their length remains low across all sites, reflecting the fairly uniform nature of Elmenteitan blade production. Production of morphologically aberrant blades does appear to be less frequent at the quarry site itself, where termination flaws dominate. The rate of termination flaws is the only variable to clearly pattern onto distance from the quarry. This almost certainly is due to the aforementioned reduction in blade size with distance. Smaller blade cores permit the production of normally terminating blades from a greater range of applied force than do larger blade cores, where force must be applied more precisely to prevent premature termination. Platform shattering and bulbar sheering (results of a misaligned punch during blade removal) typically accounts for only 15-20\% of production errors. The appearance of high proportions of length:thickness and bulb damage errors at Olopilukunya is due to the low rate of errors within a small assemblage and probably does not indicate a different behavioral or taphonomic pattern at that site. 


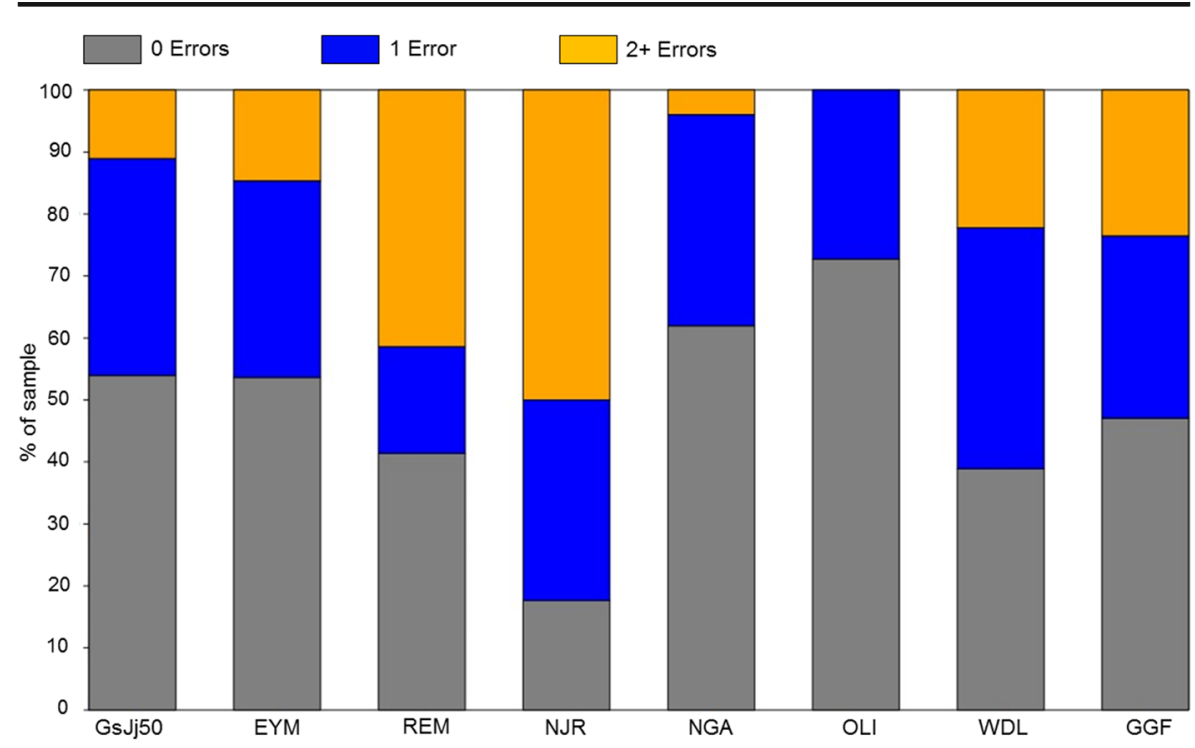

Fig. 8 Proportions of blades with no errors, single errors, and multiple errors in each Elmenteitan assemblage. Sites are arranged left-to-right by the distance from the Mt. Eburru obsidian source

\section{Discussion}

\section{Interpretation of Error Scores}

Production errors can be a useful correlate for evaluating the skill employed during stone tool manufacture, allowing for an inroad into discussing lithic learning in the archaeological record. First, error rates fluctuate unevenly in relation to blade length. This does not match expectations that errors should be more common on the longest blades and the shortest blades with fewer errors on easier to manufacture mid-sized blades. If anything, the longest blades demonstrate the lowest rates of blade production errors, even though successfully detaching blades longer than $15 \mathrm{~cm}$ requires very precise attention to force and support of the release surface. Additionally, the straight and long blades should be the first to be selected as blanks for Elmenteitan tools and modified such they were not included in this analysis or were curated away from the quarry. There are fewer total blades in this $15-25 \mathrm{~cm}$ size range, making it difficult to determine how much of this pattern results from taphonomic processes. An alternative explanation (assuming the pattern is reflective of actual error rates) is that higher skilled individuals were more involved in the early stages of core reduction. A high error rate for smaller blades is more reasonable, as smaller striking platforms impose additional challenges to successful blade production. An increase in production errors around blade lengths of $12-15 \mathrm{~cm}$ is less straightforward. Previous analyses have shown that several aspects of Elmenteitan core morphology become established at this length, with additional core transformations occurring at lengths of $\sim 7 \mathrm{~cm}$ (Goldstein 2018). It is possible that the spikes in error rates at these two points relate to these particularly delicate and difficult stages of core reduction, or stages where the flaking mechanism (direct vs. indirect percussion) changes. 


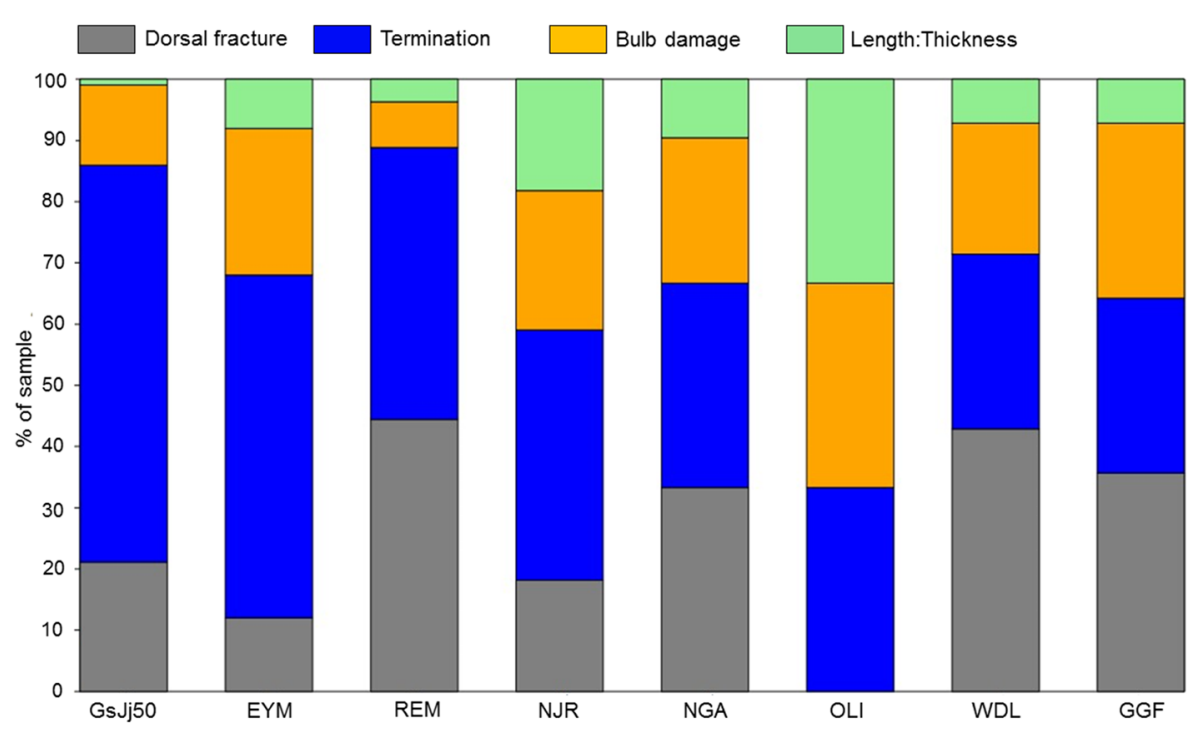

Fig. 9 Proportions of the types of errors identified in each Elmenteitan assemblage. Sites are arranged left-toright by the distance from the Mt. Eburru obsidian source

The only other variable to correlate strongly with error rates was curvature. Highly curved blades exhibit fewer errors than do flattest blades, as should be expected given conchoidal fracture mechanics. One possibility is that decreasing curvature through the reduction sequence leads to increasingly steep platform angles, which increases the likelihood of step or hinge terminations. Most of the platform rejuvenations and core modification flakes from the Elmenteitan Obsidian Quarry assemblage appear to be efforts to prevent or alleviate this exact issue (Goldstein 2018). As only high, rather than low, curvatures were counted as production errors, this does not constitute an issue of double-counting correlated production mistakes.

These relationships may explain some of the observed patterns in error scores between the other Elmenteitan sites. Some technical aspects of Elmenteitan core design and reduction trajectories are increasing the rate of errors on blades with certain lengths. While the blade length distributions are comparable across all assemblages, Ngamuriak has the largest blades on average and exhibits a low error score. The Elmenteitan Obsidian Quarry also has a relatively high average error score despite the prevalence of very long blades. Blades from Wadh Lang'o and Gogo Falls near the end of the Elmenteitan exchange sphere skew slightly smaller and have somewhat higher error rates. Within the Central Rift Valley sites, the shorter blade assemblages at Remnant and Njoro River Cave display higher error rates than the longer blades at Enkapune Ya Muto. Olopilukunya has the shortest blade assemblage and yet has the lowest average error score. This is a very small sample resulting from limited excavations, making it difficult to interpret with much confidence. Differences in error-to-length relationships are not proportional across all sites. Differences in blade length distributions between sites are not substantial enough to explain the disparities in error scores between sites. This is to say that factors beyond the technical aspects of core reduction play a role in the exact occurrence of blade production mistakes at the sampled sites. Those factors 
are likely complex and idiosyncratic, relating largely to the circumstances of the individuals making stone tools in these particular places at particular times.

\section{Evidence for Learning}

Inter-site variation in error rates can be used to interpret how community-level lithic learning was structured in the past. I emphasize that these discussions will always be speculative and that the strength of derived conclusions depends heavily on the size of samples and quality of data. Interpreting the Elmenteitan production error patterns is intended as an exercise in developing frameworks for discussing communities-ofpractice involved in knowledge transmission and not a conclusive argument about Elmenteitan social structure.

As discussed above, elevated error rates at the very distant sites of Wadh Lang'o and Gogo Falls can be explained by the technical difficulties of managing the smaller cores curated so far from the source. Particularly, high average scores were calculated for the Elmenteitan Obsidian Quarry site on Mt. Eburru, the Remnant site on the high-altitude Mau Escarpment, and the mortuary site of Njoro River Cave near Lake Nakuru in the Central Rift Valley. These sites had very different functions, making it difficult to connect communities-of-practice involving lithic learning with a specific suite of ritual or economic activities. Regional proximity to the Elmenteitan Obsidian Quarry is the only shared variable among the sites with very high error rates.

Error rates quantified here for Njoro River Cave may explain why Leakey and Leakey (1950: 74) initially described the assemblage as a "degenerate" and "poorlymade" example of the Elmenteitan industry. One interpretive problem is that Njoro River Cave was used a specialized cremation site. Strata were mixed by Elmenteitan mortuary practices, and it is not clear how much of the assemblage originated at other locations and was subsequently transported to the site over the course of decades or centuries (as suggested by Leakey and Leakey 1950). Blades may also have entered incidentally as the personal tool kits of cremated individuals, or through a combination of many processes. Even so, the high rate of errors stands out from habitation or rockshelter sites where error rates are low, and so, the Njoro assemblage may have derived from a different pattern of activities. The Remnant Site sample is also problematic in that it consists of few pieces from a small excavation area, possibly representing a single knapping episode (Ambrose 1984a). Despite potential biases, there is some reason to believe these error rates do reflect a greater contribution from learners. Single errors could be explained by relaxed pressures to conserve material near the obsidian sources; however, it is the presence of repetitive errors (a stronger signal of novices) that is driving variation. Much like Njoro River Cave, Remnant is an atypical Elmenteitan site. Though the lithic assemblage is comparable to other Elmenteitan open-air habitations, the Remnant Site is in the high-altitude Mau Escarpment. Cold and forested areas are generally avoided by recent herders due to the increased risk to livestock, and isotopic studies show no evidence that either Elmenteitan or SPN communities were engaged in vertical transhumance to these altitudes (Balasse and Ambrose 2005; Janzen 2015). Again, it is unclear how the atypical nature of these sites relates to the behaviors surrounding lithic production that generated blades with more errors.

The Elmenteitan Obsidian Quarry sample presents more robust evidence for lithic learning. This is a much larger and more representative sample, demonstrating a complex 
pattern of error rates throughout the blade reduction sequence. The diversity of core morphologies, high rates of expedient cores, and use of lower quality raw materials are all signs of lithic learning (see Milne 2012; Shelley 1990: 191), and all of these are noted for the Elmenteitan Obsidian Quarry (Goldstein and Munyiri 2017). The level of core reduction (down to exhaustion) evident at the quarry is well beyond what is necessary to prepare cores and cannot be explained solely through restocking transported tool kits or provisioning tools for tasks on site. One possible explanation for this intensity of blade production is that a large percentage of the quarry debris reflects learning and practice by novices.

Another line of evidence supporting learner behavior at the Elmenteitan Obsidian Quarry is the distribution of errors across blade sizes. Figure 10 plots the measured distribution of error rates across blade lengths against the expected patterns for novices and experts presented above. As discussed earlier, error rates are low for the larger and more difficult to produce blades and then increase as cores become smaller and, theoretically, more manageable. Error rates should be concentrated earlier in a blade production sequence if experts alone are producing cores (see Bamforth and Finlay 2008; Grimm 2000; Finlay 1997; Stout 2002). The sharp spike in core error rates may reflect hand-offs from experts to novices, as expected in "scaffolding" models for lithic learning discussed by d'Errico and Banks (2015) and Ferguson (2008). Experts managed cores through the most difficult early stages, and then many of these could have been then used for novice practice while others were reserved for transport back to the home communities. In many ways this is logical, experts must also be present for learning to occur. Experts may have been guiding or assisting novice knapping by fixing mistakes and rejuvenating cores (Stout 2002: 702). Error rates may thus be distorted by a mixed signature of skill that was, in essence, part of the teaching process.

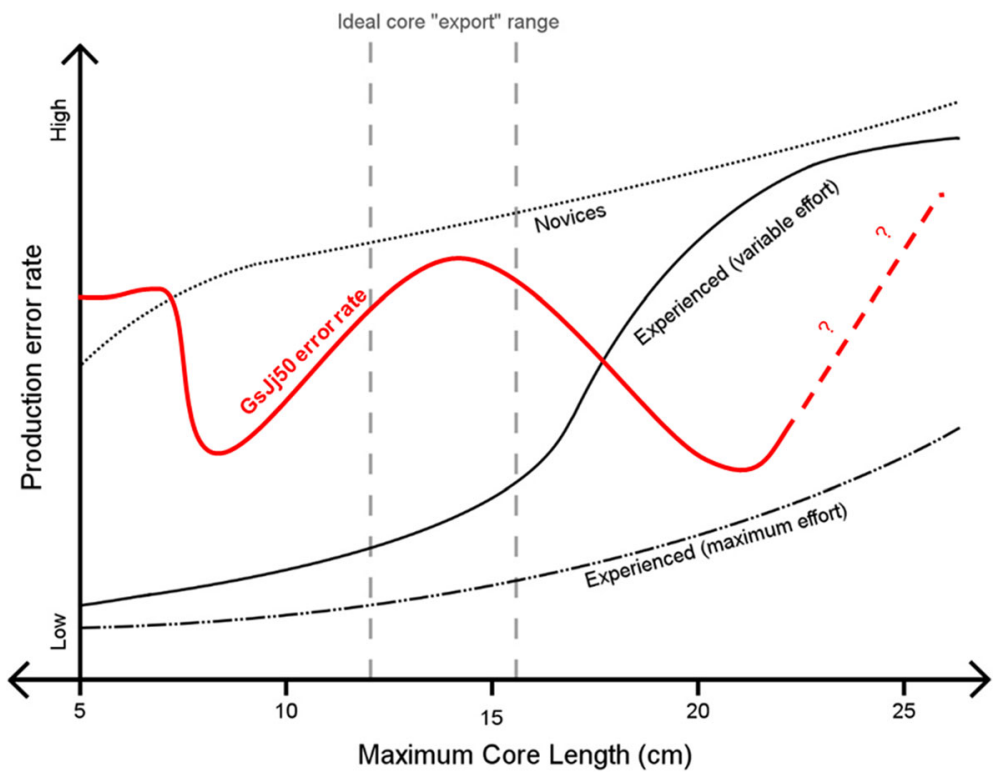

Fig. 10 Actual pattern of blade production error rates through the reduction sequence in the Elmenteitan Obsidian Quarry (red line) compared to expectations for novice and expert production, based on error rates in Fig. 6 


\section{Composition and Organization of "Communities-of-Practice"}

Places of raw material abundance are ideal locations to look for evidence of the learning and apprenticeship that would identify a community-of-practice component to social institutions involved in lithic quarrying (Finlay 1997; Ferguson 2008; Shelley 1990; Milne 2012: 335). This would be amplified in the case of the Elmenteitan, who relied so heavily on obsidian for tool production. Learners and novices inherently make more mistakes and "waste" raw material at higher rates (Ferguson 2008; Finlay 1997; Pigeot 1990; Shelley 1990; Walthall and Koldehoff 2017). At habitation sites far from the quarry where obsidian access was constrained (see Goldstein 2014), families may have been hesitant to turn over cores to novices. A more logical solution would be focus learning near the Mt. Eburru Elmenteitan Obsidian Quarry.

Current models for Elmenteitan obsidian acquisition center on the existence of an obsidian distribution or exchange network, that likely involved some combination of direct and indirect acquisition (Ambrose 2001; Gifford-Gonzalez 1998; Robertshaw $1988,1990)$. It is unlikely that a whole family would travel to the quarry given the basic constraints of pastoral lifeways, wherein mobility is structured around the constantly changing locations of rainfall and good pasture (after Dahl and Hjort 1976). This is evidenced by the lack of habitation sites nearby. Therefore, quarrying groups were probably composed of individuals from multiple lineages of family groups. This too is supported archaeologically in the diverse range of ceramics, likely reflecting individuals from multiple family groups, possibly even from multiple lineages (Goldstein and Munyiri 2017). Given a heterogeneous distribution of "experts" and "novices" across the landscape, this kind of multi-community involvement might be necessary in order to facilitate the passing on of lithic reduction knowledge. Binford (2001) notes that such logistical acquisition ventures may be ad hoc; however, the various lines of evidence presented here are more in line with Milne's (2012) expectations for more enduring "cooperative projects" of quarry access.

Skill, age, and gender likely structured participation. Experimental and ethnographic evidence suggests that knapping apprenticeship usually begins between the early to late teens (Ferguson 2008; Pigeot 1990; Stout 2002; but see Weedman 2002a, b: 738). This is typically due to the timing of motor skill and upper body strength development (Finlay 1997, 2015; Shea 2006). Among eastern African herders, this is the same age that young men are ideally inducted into age-grade type institutions or warriorhood. It is this more expendable labor pool that is tasked with military action or defense, taking livestock to markets, or other long-distance trips away from the home community. Within the age-grade systems of ethnohistoric herders, groups of young warriors focus activities away from normal habitation areas in places like rock-shelters and forests (Mbae 1990).

Each family may also choose to have only certain children inducted based on the number and ages of their children (e.g. the labor pool needed for herding) or the particular dynamics or traditions of their lineage group. Individual or overlapping agesets are thus often composed of individuals with different levels of physical maturity, with younger age-set groups being subordinate to older age-sets while practical skills are passed on in informal environments (Peristiany 1951). Participants in ancient quarrying events would therefore have formed a community-of-practice in which 
knowledge and skills were passed down from more- to less-experienced knappers. Conditions structuring ethnographic age-grades are based in the realities of pastoralism in arid East Africa. Ancient communities-of-practice involving lithic learning likely differed significantly from these more recent systems but may have shared some basic organizational similarities.

The role of novices at the quarry is speculative, but I suggest that individual participation could have varied based on an individual's relative age and experience. For example, novices on their first quarrying trip may have only been allowed to help extract and test nodules, followed by being scaffolded into actual core preparation once basic skills were mastered, or on subsequent trips. Novices can be self-stratified within their peer groups based on age or inter-personal dynamics, but stratification can also be imposed on novices based on observations and judgments of accompanying experts (e.g. Stout 2002). d'Errico and Banks (2015) codify these possibilities with terms like "sequential transmission" where skills are taught in a specific order necessary for the end goal, and "modular transmission," wherein several independent skills must be acquired and combined to achieve that goal. Given the demands of Elmenteitan technology, the Elmenteitan case study likely involved complex combinations of multiple transmission types.

Quarrying trips would also have been prime opportunities to impart other forms of knowledge onto younger generations (e.g. Binford 2001: 467), and the presence of errors at the highland forest Remnant Site and the mortuary rock-shelter site of Njoro River Cave hint at this possibility. The highland Mau Forest around Mt. Eburru hosts a wealth of medicinal plants not available in the lower elevation savannas, many of which are still being used in traditional medicines today (Pers. Obs.). Learning about and acquiring useful plants, ochre, and other materials could easily have been components of such communities-of-practice. More importantly, this same communities-ofpractice could have been important in ritual and spiritual dimensions of early pastoralism. Njoro River Cave is one of several known Elmenteitan specialized burial sites, all of which are located near the obsidian rich Central Rift Valley, and not in the southwestern savannas where habitations are concentrated. As of yet, no substantial Elmenteitan open-air herding sites have been described within the Central Rift. High altitude and special purpose sites clustered around Mt. Eburru are linked by similarly high blade error rates, making it possible that the same groups of novices were involved in a wide range of logistical activities in this region. This would reflect a more modular form of learning socially embedded tasks.

Learning is a part of enculturation. If participation in communities-of-practice involving obsidian quarrying and lithic learning involved the imparting of such wide domain of what Ingold (1993: 443) referred to as "knowledgeable practice," then lithic learning may have become important in ideas of personhood or community membership. Certainly, the centralization of learning at a quarry site would help explain how the technological homogeneity of the Elmenteitan was maintained across a diverse landscape over 2000 years. The Elmenteitan Obsidian Quarry and the surrounding special purpose sites would also have been ideal venues for communities from diverse regions to exchange information about rainfall, livestock epidemics, ceremonies, or other important events. Perhaps more importantly, engagement of novices in learning tasks at the quarries creates social bonds between cohorts. Similar systems based on shared participation in age-grades are crucial for maintaining reciprocal networks of 
stock-friendships between affiliated communities (Gulliver 1971: 18; Homewood 2008; Salzmann 1971). These networks underlay recent pastoralist strategies for economic resilience in the face of unpredictable climates and heterogeneous resource distributions (Bernsten 1976; Bollig 2000).

\section{Conclusion}

Identifying the products of knowledge transmission in the past is an important, but difficult, exercise. The durability and ubiquity of stone tools make them ideal for generating approaches for evaluating and interpreting evidence of learners in human prehistory. Here, I have attempted to contribute to a growing archaeology of learning through a case study focused on patterns of lithic production among Elmenteitan herding communities in Kenya. Assuming that novices are more likely to make mistakes in the process of learning, the rate and proportion of production errors on obsidian blades provide a useful, though course, correlate for identifying which assemblages may have had a greater contribution from novices. Criteria for "errors" are specific to the Elmenteitan lithic industry, which emphasized uniform blade production. Scoring errors is another potential source of bias. Too much or too little weight may be given to some blade production mistakes. Both a hinge termination and a platform shattering receive the same error score, when some features may be more or less indicative of low skill (see experimental results in Ferguson 2008 and Eren et al. 2015). The decision to more heavily weight multiple step fractures is justified, as repeated mistakes are a stronger line of evidence for novices (Bamforth and Finlay 2008). Future blade reduction experiments and other actualistic projects - informed by these results - will help test and improve the validity of the scoring method by determining the technical causes and relationships between different types of errors. Furthermore, this study can serve as a baseline for more expanded studies of learning that incorporate formal and informal tools, as well as fragmentary debris. Studies that incorporate the totality of the lithic assemblage are necessary to generate higherresolution assessments of lithic learning in prehistory.

Learning to produce blades was likely a small component of lithic knowledge transfer. People had to learn about the location of lithic resources, how to extract them, how to prepare cores, how to reduce those cores, and how to make and use tools. That knowledge is differentially distributed within a community, often along the lines of age, gender, and lineage. Admitting that learning occurred in the past necessarily requires us to evaluate the social mechanisms of learning. After all, the ultimate goal is not to simply identify novices but to understand the structure of knowledge transmission and its implications for other cultural systems (e.g. Bamforth and Finlay 2008). Scholarship outlining communities-of-practice (Dorland 2017; Wenger 1998) provides a useful and flexible vocabulary for discussing learning and praxis in non-Western societies with informal learning environments. I have drawn on those ideas here to provide an interpretation for the preliminary results of error rate quantifications that support more evidence for learning at the Elmenteitan Obsidian Quarry and surrounding sites. Lithic learning could have been integrated into systems that maintained connectivity between Elmenteitan communities as discussed by Ambrose (2001) as a reason for the remarkable homogeneity in material culture and obsidian selection among this group. These 
cultural strategies may have been different from those developed by the other herder entities in eastern Africa during the Pastoral Neolithic period, which may have affected the persistence and patterning of these archaeological groups.

Though only a theoretical exercise with a limited dataset, these kinds of interpretative explorations generate more interesting testable hypotheses that can advance this, and broader, archaeological studies of learning. Given that Homo sapiens universally exhibit complex and deeply cultural patterns of knowledge transmission (d'Errico and Banks 2015), attempts to identify novices in the archaeological record is not only important for studying the spread of African pastoralism, but also for all global studies of lithic assemblages. In order for studies of lithic learning to progress, experimental projects, ethnoarchaeological studies, and theoretical discussions must exist in an ongoing dialectic with analyses of archaeological assemblages. Results from each of these domains will improve the framework for continued work in others. A holistic approach to studying lithic learning can contribute to the broader study of learning among human societies, both past and present.

Acknowledgments This research was funded by a grant from the National Science Foundation (BCS1439123) and conducted under Kenyan NACOSTI Permit no. P/14/4316/1875. I am indebted to the National Museums of Kenya, especially Dr. Emmanuel Ndiema, Dr. Purity Kiura, Dr. Christine Ogala, and John M. Munyiri for the access to collections and for critical assistance during these analyses. I also thank the original excavators of the sites included in this project. Comments and suggestions by Dr. Fiona Marshall and Dr. Stanley Ambrose greatly improved the quality of this manuscript; all remaining errors are solely my responsibility.

Funding Information Open access funding provided by Max Planck Society.

Open Access This article is distributed under the terms of the Creative Commons Attribution 4.0 International License (http://creativecommons.org/licenses/by/4.0/), which permits unrestricted use, distribution, and reproduction in any medium, provided you give appropriate credit to the original author(s) and the source, provide a link to the Creative Commons license, and indicate if changes were made.

\section{References}

Agbe-Davies, A. S. (2009). Scales of analysis, scales of value: archaeology at Bush Hill House. Barbados. International Journal of Historical Archaeology, 13(1), 112-126.

Ambrose, S. H. (1980). Elmenteitan and other late Pastoral Neolithic adaptations in the central highlands of East Africa. In R. E. Leakey \& B. A. Ogot (Eds.), Proceedings of the eighth Panafrican congress of prehistory and quaternary studies, Nairobi (pp. 279-282). Nairobi: The Louis Leakey Memorial Institute for African Prehistory.

Ambrose, S. H. (1982). Archaeology and linguistic reconstructions of history in East Africa. In C. Ehret \& M. Posnansky (Eds.), The archaeological and linguistic reconstructions of African history (pp. 104-157). Berkeley: University of California Press.

Ambrose, S. H. (1984a). The introduction of pastoral adaptations to the highlands of East Africa. In J. D. Clark \& S. A. Brandt (Eds.), From hunters to farmers: the causes and consequences of food production in Africa (pp. 212-239). Berkeley: University of California Press.

Ambrose, S. H. (1984b). Excavations at Deloraine, Rongai, 1978. Azania, 20, 29-67.

Ambrose, S. H. (1998). Chronology of the Later Stone Age and food production in East Africa. Journal of Archaeological Science, 25(4), 377-392.

Ambrose, S. H. (2001). East African Neolithic. In P. N. Peregrine \& M. Ember (Eds.), Encyclopedia of prehistory volume 1: Africa (pp. 97-109). New York: Kluwer Academic/Plenum. 
Ambrose, S. H. (2002). Small things remembered: origins of early microlithic industries in sub-Saharan Africa. Archaeological papers of the American Anthropological Association, 12(1), 9-29.

Ambrose, S. H. (2012). Obsidian hydration dating and source exploitation studies in Africa. In I. Liritzis \& C. M. Stevenson (Eds.), The dating and provenance of obsidian and ancient manufactured glasses (pp. 5672). Albuquerque: University of New Mexico Press.

Andrefsky, W. (2016). Numerical Types and Inspectional Types: Evaluating Shape Characterization Procedures. North American Archaeologist, 7(2), 95-112.

Andrews, B. (2003). Measuring prehistoric craftsman skill: contemplating its application to Mesoamerican core-blade research. In K. Hirth (Ed.), Mesoamerican lithic technology: experimentation and interpretation (pp. 208-219). Salt Lake City: University of Utah Press.

Apel, J. (2008). Knowledge, know-how and raw material-the production of Late Neolithic flint daggers in Scandinavia. Journal of Archaeological Method and Theory, 15(1), 91-111.

Arthur, K. W. (2010). Feminine knowledge and skill reconsidered: women and flaked stone tools. American Anthropologist, 112(2), 228-243.

Balasse, M., \& Ambrose, S. H. (2005). Mobilité altitudinale des pasteurs néolithiques dans la vallée du Rift (Kenya): Premiers indices de l'analyse du $\delta 13 \mathrm{C}$ de l'émail dentaire du cheptel domestique. Anthropozoologica, 40(1), 147-166.

Bamforth, D. B., \& Finlay, N. (2008). Introduction: archaeological approaches to lithic production skill and craft learning. Journal of Archaeological Method and Theory, 15(1), 1-27.

Bernsten, J. L. (1976). The Maasai and their neighbors: variables of interaction. African Economic History, 2 , $1-11$.

Binford, L. R. (1979). Organization and Formation Processes: Looking at Curated Technologies. Journal of Anthropological Research, 35(3), 255-273.

Binford, L. R. (2001). Constructing frames of reference: an analytical method for archaeological theory building using ethnographic and environmental data sets. Berkeley: University of California Press.

Bleed, P. (2008). Skill matters. Journal of Archaeological Method and Theory, 15(1), 154-166.

Bodu, P., Karlin, C., \& Ploux, S. (1990). Who's who? The Magdalenian flintknappers of Pincevent (France). In E. Cziesla, S. Eickhoff, N. Arts, \& D. Winther (Eds.), The big puzzle. International symposium on refitting stone artefacts, Mon Repos 1987. Bonn: Holos.

Bollig, M. (2000). Unmaking a market: the encapsulation of a regional trade network. Northwest Namibia between the 1860s and 1950s. In W. J. G. Möhlig \& M. Bollig (Eds.), Frühe kolonialgeschichte Namibias 1880-1930 (pp. 11-29). Berlin: Rüdiger Köppe.

Bourdieu, P. (1977). Outline of a theory of practice. Cambridge: Cambridge University Press.

Bower, J. R. (1991). The Pastoral Neolithic of East Africa. Journal of World Prehistory, 5(1), 49-82.

Bower, J. R., Nelson, C. M., Waibel, A. F., \& Wandibba, S. (1977). The University of Massachusetts' Later Stone Age/Pastoral "Neolithic" comparative study in Central Kenya: An overview. Azania, 12(1), 19-45.

Boyd, R., \& Richerson, P. J. (1985). Culture and the evolutionary process. London: University of Chicago Press.

Bradley, B., \& Stanford, D. (2004). The North Atlantic ice-edge corridor: a possible Paleolithic route to the new world. World Archaeology, 36(4), 459-478.

Cavalli-Sforza, L. L., \& Feldman, M. W. (Eds.). (1981). Cultural transmission and evolution: a quantitative approach (no. 16). Princeton: Princeton University Press.

Clark, G. (2003). Indigenous transfer of La Pérouse artefacts in the Southeast Solomon Islands. Australian Archaeology, 57(1), 103-111.

Conkey, M. W. (1991). Contexts of action, contexts for power: material culture and gender in the Magdalenian. In M. W. Conkey \& J. M. Gero (Eds.), Engendering archaeology: women and prehistory (pp. 57-92). Oxford: Blackwell.

Costin, C. L., \& Hagstrum, M. B. (1995). Standardization, labor investment, skill, and the organization of ceramic production in late prehispanic highland Peru. American Antiquity, 60(4), 619-639.

Costin, C. L. (2001). Craft production systems. In G. M. Feinman \& T. D. Price (Eds.), Archaeology at the millennium (pp. 273-327). Boston: Springer.

Crabtree, D. E. (1972). An introduction to Flintworking. In Occasional papers of the Museum of Idaho State University 28. Pocatello: Museum of Idaho State University.

Creese, J. L. (2012). Social contexts of learning and individual motor performance. In W. Wendrich (Ed.), Archaeology and apprenticeship: body knowledge, identity, and communities of practice (pp. 43-60). Tucson: University of Arizona Press.

d'Errico, F., \& Banks, W. E. (2015). The archaeology of teaching: a conceptual framework. Cambridge Archaeological Journal, 25(4), 859-866. 
Dahl, G., \& Hjort, A. (1976). Having herds: pastoral herd growth and household economy. Stockholm studies in social anthropology. Stockholm: Liber Tryck.

Dobres, M. A., \& Hoffman, C. R. (1994). Social agency and the dynamics of prehistoric technology. Journal of Archaeological Method and Theory, 1(3), 211-258.

Dorland, S. G. H. (2017). Maintaining traditions: a study of southern Ontario Late Woodland ceramics through a communities-of-Practice approach. Journal of Archaeological Method and Theory. https://oi. org/10.1007/s10816-017-9362-y.

Dugstad, S. A. (2010). Early child caught knapping. A novice early Mesolithic flintknapper in south-western Norway. Socialisation: recent research on childhood and children in the past. Stavanger: AmS-Skrifter, 23, 65-74.

Eerkens, J. W. (2000). Practice makes within 5\% of perfect: visual perception, motor skills, and memory in artifact variation. Current Anthropology, 41(4), 663-668.

Eerkens, J. W., \& Bettinger, R. L. (2001). Techniques for assessing standardization in artifact assemblages: can we scale material variability? American Antiquity, 66(3), 493-504.

Eren, M. I., Lycett, S. J., Roos, C. I., \& Sampson, C. G. (2011). Toolstone constraints on knapping skill: Levallois reduction with two different raw materials. Journal of Archaeological Science, 38(10), 27312739.

Eren, M. I., Patten, R. J., O’Brien, M. J., \& Meltzer, D. J. (2013). Refuting the technological cornerstone of the Ice-Age Atlantic crossing hypothesis. Journal of Archaeological Science, 40(7), 2934-2941.

Eren, M. I., Buchanan, B., \& O’Brien, M. J. (2015). Social learning and technological evolution during the Clovis colonization of the New World. Journal of Human Evolution, 80, 159-170.

Ferguson, J. R. (2003). An experimental test of the conservation of raw material in flintknapping skill acquisition. Lithic Technology, 28(2), 113-131.

Ferguson, J. R. (2008). The when, where, and how of novices in craft production. Journal of Archaeological Method and Theory, 15(1), 51-67.

Finlay, N. (1997). Kid knapping: the missing children in lithic analysis. In J. Moore \& E. Scott (Eds.), Invisible people and processes: writing gender and childhood into European archaeology (pp. 203-212). Leicester: Leicester University Press.

Finlay, N. (2008). Blank concerns: issues of skill and consistency in the replication of Scottish Later Mesolithic blades. Journal of Archaeological Method and Theory, 15(1), 68-90.

Finlay, N. (2015). Kid-knapped Knowledge: Changing Perspectives on the Child in Lithic Studies. Childhood in the Past, 8(2), 104-112.

Flenniken, J. J. (1978). Reevaluation of the Lindenmeier Folsom: a replication experiment in lithic technology. American Antiquity, 43(3), 473-480.

Foner, A., \& Kertzer, D. (1978). Transitions over the life course: lessons from age-set societies. American Journal of Sociology, 83(5), 1081-1104.

Gifford, D. P., Isaac, G. L., \& Nelson, C. M. (1980). Evidence for predation and pastoralism at prolonged drift: a Pastoral Neolithic site in Kenya. Azania, 15(1), 57-108.

Gifford-Gonzalez, D. P. (1998). Gender and early pastoralists in East Africa. In S. Kenya (Ed.), Gender in African prehistory (pp. 115-138). London: AltaMira Press.

Goldstein, S. T. (2014). Quantifying endscraper reduction in the context of obsidian exchange among early pastoralists in southwestern Kenya. Lithic Technology, 39(1), 3-19.

Goldstein, S. T. (2018). Picking up the pieces: reconstructing lithic production strategies at a Late Holocene obsidian quarry in southern Kenya. Journal of Field Archaeology, 43(2), 85-101.

Goldstein, S. T., \& Munyiri, J. (2017). The Elmenteitan Obsidian Quarry (GsJj50): new perspectives on obsidian access and exchange during the Pastoral Neolithic in southern Kenya. African Archaeological Review, 34(1), 43-73.

Goodale, N., \& Andrefsky Jr., W. (Eds.). (2015). Lithic technological systems and evolutionary theory. Cambridge: Cambridge University Press.

Grimm, L. (2000). Apprentice flintknapping: relating material culture and social practice in the Upper Paleolithic. In J. S. Derevenski (Ed.), Children and material culture (pp. 53-71). New York: Routledge.

Gulliver, P. H. (1971). Neighbours and networks: the idiom of kinship in social action among the Ndendeuli of Tanzania. Berkeley: University of California Press.

Hayden, B., \& Cannon, A. (1984). Interaction inferences in archaeology and learning frameworks of the Maya. Journal of Anthropological Archaeology, 3(4), 325-367.

Hildebrand, E. A., \& Grillo, K. M. (2012). Early herders and monumental sites in eastern Africa: dating and interpretation. Antiquity, 86(332), 338-352.

Hiscock, P. (2014). Learning in lithic landscapes: a reconsideration of the hominid "toolmaking" niche. Biological Theory, 9(1), 27-41. 
Högberg, A. (2008). Playing with flint: tracing a child's imitation of adult work in a lithic assemblage. Journal of Archaeological Method and Theory, 15(1), 112-131.

Högberg, A., Gärdenfors, P., \& Larsson, L. (2015). Knowing, learning, and teaching-how Homo became Docens. Cambridge Archaeological Journal, 25(4), 847-858.

Hogg, A. G., Hua, Q., Blackwell, P. G., Niu, M., Buck, C. E., Guilderson, T. P., Heaton, T. J., Palmer, J. G., Reimer, P. J., Reimer, R. W., Turney, C. S. M., \& Zimmerman, S. R. H. (2013). SHCal13 southern hemisphere calibration, 0-50,000 years cal BP. Radiocarbon, 55, 1-15.

Holdaway, S., \& Allen, H. (2012). Placing ideas in the land: practical and ritual training among the Australian Aborigines. In W. Wendrich (Ed.), Archaeology and apprenticeship: body knowledge, identity, and communities of practice (pp. 79-98). Tucson: University of Arizona Press.

Homewood, K. M. (2008). Ecology of African pastoralist societies. Athens: Ohio University Press.

Ingold, T. (1993). The temporality of the landscape. World Archaeology, 25(2), 152-174.

Ingold, T. (2010). Bringing things to life: creative entanglements in a world of materials. World, 44, 1-25.

Janzen, A. (2015). Mobility and herd management strategies of early pastoralists in south-central Kenya, 3000-1200 BP (Doctoral dissertation, UC Santa Cruz).

Julien, C. K., \& Julien, M. (1994). Prehistoric technology: a cognitive science? In C. Renfrew \& E. Zubrow (Eds.), The ancient mind, elements of cognitive archaeology (pp. 152-163). Cambridge: Cambridge University Press.

Kuper, R., \& Kröpelin, S. (2006). Climate-controlled Holocene occupation in the Sahara: motor of Africa's evolution. Science, 313(5788), 803-807.

Lane, P. J., Ashley, C., Seitsonen, O., Harvey, P., Mire, S., \& Odede, F. (2007). The transition to farming in eastern Africa: new faunal and dating evidence from Wadh Lang'o and Usenge, Kenya. Antiquity, 81(311), 62-81.

Lassen, R., \& Williams, T. (2015). Variation in flintknapping skill among Folsom-era projectile point types: a quantitative approach. Journal of Archaeological Science: Reports, 4, 164-173.

Lave, J., \& Wenger, E. (1991). Situated learning: legitimate peripheral participation. Cambridge: Cambridge University Press.

Leakey, L. S. B., \& Leakey, M. D. (1950). Excavations at the Njoro River Cave: Stone Age burials in Kenya colony. London: Clarendon Press.

Leakey, M. D., Leakey, L. S. B., Game, P. M., \& Goodwin, A. J. H. (1943). Report on the excavations at Hyrax Hill, Nakuru, Kenya Colony, 1937-1938. Transactions of the Royal Society of South. Africa, 30(4), 271-409.

Lemonnier, P. (1993). Technological choices: transformations in material cultures since the Neolithic. New York: Routledge.

Lenoir, M. (1975). Remarks on fragments with Languette fractures. In E. H. Swanson (Ed.), Lithic technology: making and using stone tools (pp. 129-132). Paris: Morton Publishers.

Leroi-Gourhan, A. (1964). Les religions de la préhistoire: paléolithique (Vol. 51). Paris: Presses univ. de France.

Lillehammer, G. (2015). 25 years with the 'child'and the archaeology of childhood. Childhood in the Past, $8(2), 78-86$.

Marshall, F. B. (1990). Origins of specialized pastoral production in East Africa. American Anthropologist, 92(4), 873-894.

Marshall, F. B., \& Hildebrand, E. A. (2002). Cattle before crops: the beginnings of food production in Africa. Journal of World Prehistory, 16(2), 99-143.

Marshall, F., Stewart, K., \& Barthelme, J. (1984). Early domestic stock at Dongodien in northern Kenya. Azania, 19(1), 120-127.

Marshall, F. B., Grillo, K. M., \& Arco, L. (2011). Prehistoric pastoralists and social responses to climatic risk in East Africa. In N. Miller, K. Moore, \& K. Ryan (Eds.), Sustainable lifeways: cultural persistence in an ever-changing environment (pp. 39-74). Philadelphia: University of Pennsylvania Museum of Archaeology and Anthropology Series, Penn Press.

Mbae, N. N. (1990). The ethnoarchaeology of Maasai settlements and refuse disposal patterns in the Lemek area. In P. Robertshaw (Ed.), Early pastoralists of south-western Kenya (Vol. 11, pp. 279-292). Nairobi: Memoirs of the British Institute in Eastern Africa.

Merrick, H. V., \& Brown, F. H. (1984). Obsidian sources and patterns of source utilization in Kenya and northern Tanzania: some initial findings. African Archaeological Review, 2(1), 129-152.

Merrick, H. V., Brown, F. H., \& Connelly, M. (1990). Sources of the obsidian at Ngamuriak and other southwestern Kenyan sites. In P. Robertshaw (Ed.), Early pastoralists of south-western Kenya (Vol. 11, pp. 173-182). Nairobi: Memoirs of the British Institute in Eastern Africa. 
Merrick, H. V., \& Monaghan, M. C. (2010). The Date of the Cremated Burials in Njoro River Cave. Azania: Archaeological Research in. Africa, 19(1), 7-11.

Milne, S. B. (2005). Palaeo-Eskimo novice flintknapping in the eastern Canadian Arctic. Journal of Field Archaeology, 30(3), 329-345.

Milne, S. B. (2012). Lithic raw material availability and palaeo-Eskimo novice flintknapping. In W. Wendrich (Ed.), Archaeology and apprenticeship: body knowledge, identity, and communities of practice (pp. 119144). Tuscon: The University of Arizona Press.

Minar, C. J., \& Crown, P. L. (2001). Learning and craft production: an introduction. Journal of Anthropological Archaeology, 57(4), 369-380.

Nelson, C. M. (1980). The Elmenteitan lithic industry. In R. E. Leakey \& B. A. Ogot (Eds.), Proceedings of the 8th Panafrican congress of prehistory and quaternary studies, Nairobi, September 1977 (pp. $275-$ 278). Nairobi: The International Louis Leakey Memorial Institute for African Prehistory.

Nelson, M. (1991). The study of technological organization. Archaeological Method and Theory, 3, 57-100.

Odner, K. (1972). Excavations at Narosura, a stone bowl site in the southern Kenya highlands. Azania, 7(1), 25-192.

Pelegrin, J. (1990). Prehistoric lithic technology: some aspects of research. Archaeological Review from Cambridge, 9(1), 116-125.

Pelegrin, J., Karlin, C., \& Bodu, P. (1988). Chaines operatoires: un outil pour le prehistorien. In J. Tixier (Ed.), Technologie prehistorique (pp. 55-62). Paris: Editions du CNRS.

Peristiany, J. G. (1951). The age-set system of the pastoral Pokot: the Sapana initiation ceremony. Africa, 21(3), 188-206.

Pigeot, N. (1990). Technical and social actors. Flintknapping specialists and apprentices at Magdalenian Etiolles. Archaeological Review from Cambridge, 9(1), 126-141.

Porr, M. (2005). The making of the biface and the making of the individual. In C. Gamble \& M. Poor (Eds.), The hominid individual in context: archaeological investigations of lower and middle Paleolithic landscapes, locales and artefacts (pp. 68-80). London: Routledge.

Robertshaw, P. T. (1988). The Elmenteitan: an early food-producing culture in East Africa. World Archaeology, 20(1), 57-69.

Robertshaw, P. T. (1990). Early pastoralists of southwestern Kenya. Nairobi: memoirs of the British Institute in Eastern. Africa, 11.

Robertshaw, P. T. (1991). Gogo Falls: excavations at a complex archaeological site east of Lake Victoria. Azania, 26(1), 63-195.

Robertshaw, P. T., \& Collett, D. T. (1983). The identification of pastoral peoples in the archaeological record: an example from East Africa. World Archaeology, 15(1), 67-78.

Roux, V., \& David, E. (2005). Planning abilities as a dynamic perceptual-motor skill: an actualist study of different levels of expertise involved in stone knapping. In V. Roux \& D. Brill (Eds.), Stone knapping: the necessary conditions for a uniquely hominin behavior (pp. 91-116). Cambridge: McDonald Institute for Archaeological Research.

Roux, V., Brill, B., \& Dietrich, G. (1995). Skills and learning difficulties involved in stone knapping: the case of stone-bead knapping in Khambhat, India. World Archaeology, 27(1), 63-87.

Salzman, P. C. (1971). Movement and resource extraction among pastoral nomads: the case of the Shah Nawazi Baluch. Anthropological Quarterly, 44(3), 185-197.

Sellet, F. (1993). Chaîne opératoire: the concept and its applications. Lithic Technology, 18(1-2), 106-112.

Shea, J. J. (2006). Child's play: reflections on the invisibility of children in the Paleolithic record. Evolutionary Anthropology: Issues, News, and Reviews, 15(6), 212-216.

Shelley, P. H. (1990). Variation in lithic assemblages: an experiment. Journal of Field Archaeology, 17, 187193.

Shennan, S. (2002). Genes, memes, and human history: Darwinian archaeology and cultural evolution. London: Thames \& Hudson.

Simons, A. (2004). The development of early pastoral societies in south-western Kenya: a study of the faunal assemblages from Sugenya and Oldorotua 1. Doctoral Dissertation, La Trobe University, Victoria.

Spencer, P. (1965). The Samburu: a study of gerontocracy in a nomadic tribe. Berkeley: University of California Press.

Stahl, J. (2008). Who were the flintknappers? A Study of Individual Characteristics. Lithic Technology, 33(2), $161-172$.

Stark, M. T., Bowser, B. J., \& Horne, L. (2008). Why breaking down boundaries matters for archaeological research on learning and cultural transmission. In M. T. Stark, B. J. Bowser, \& L. Horne (Eds.), Cultural transmission and material culture: breaking down boundaries (pp. 1-16). Tuscon: The University of Arizona Press. 
Stout, D. (2002). Skill and cognition in stone tool production: an ethnographic case study from Irian Jaya. Current Anthropology, 43(5), 693-722.

Stout, D. (2005). The social and cultural context of stone-knapping skill acquisition. In B. Bril \& V. Roux (Eds.), Stone knapping: the necessary conditions for a uniquely hominin behavior (pp. 331-340). Cambridge: McDonald Institute Monograph Series.

Surovell, T. (2012). Toward a behavioral ecology of lithic technology: cases from Paleoindian archaeology. Tuscon: The University of Arizona Press.

Takakura, J. (2013). Using lithic refitting to investigate the skill learning process: lessons from upper Paleolithic assemblages at the shirataki sites in Hokkaiso, northern Japan. In T. Akazawa, Y. Nishiaki, \& K. Aoki (Eds.), Dynamics of learning in Neanderthals and modern humans, cultural perspectives (pp. 151-173). New York: Springer Science \& Business Media.

Tignor, R. L. (1972). The Maasai warriors: pattern maintenance and violence in colonial Kenya. The Journal of African History, 13(2), 271-290.

Tostevin, G. B. (2013). Seeing lithics: a middle-range theory for testing for cultural transmission in the Pleistocene. Oakville: Oxbow Books.

Van der Leeuw, S. (1993). Giving the potter a choice. technological choices. In P. Lemonnier (Ed.), Transformation in material cultures since the Neolithic (pp. 238-288). New York: Routledge.

Walthall, J. A., \& Koldehoff, B. (2017). Hunter-Gatherer Interaction and Alliance Formation: Dalton and the Cult of the Long Blade. Plains Anthropologist, 43(165), 257-273.

Wandibba, S. (1986). Thimlich. Azania: Archaeological Research in. Africa, 21(1), 134-134.

Want, S. C., \& Harris, P. L. (2002). How do children ape? Applying concepts from the study of non-human primates to the developmental study of 'imitation' in children. Developmental Science, 5(1), 1-14.

Weedman, K. (2002a). On the spur of the moment: effects of age and experience on hafted stone scraper morphology. American Antiquity, 67(4), 731-744.

Weedman, K. (2002b). An ethnoarchaeological study of stone-tool variability among the Gamo hideworkers of southern Ethiopia. In S. Beyries \& F. Audoin-Rouzeau (Eds.), Le Travail du cuir: de la prehistorie a nos jours (pp. 131-142). Editions APDCA: Antibes.

Wendrich, W. (1999). The world according to basketry: An ethno-archaeological interpretation of basketry production in Egypt. Los Angeles: UCLA, Cotsen Institute of Archaeology Press.

Wendrich, W. (Ed.). (2013). Archaeology and apprenticeship: body knowledge, identity, and communities of practice. Tucson: University of Arizona Press.

Wenger, E. (1998). Communities of practice: learning, meaning, and identity. Cambridge: Cambridge University Press.

Whittaker, J. C. (1987). Individual variation as an approach to economic organization: projectile points at grasshopper pueblo. Arizona. Journal of Field Archaeology, 14(4), 465-479.

Wood, D., Bruner, J. S., \& Ross, G. (1976). The role of tutoring in problem solving. Journal of Child Psychology and Psychiatry, 17(2), 89-100.

Wylie, A. (1989). Archaeological cables and tacking: the implications of practice for Bernstein's 'options beyond objectivism and relativism'. Philosophy of the Social Sciences, 19(1), 1-18. 